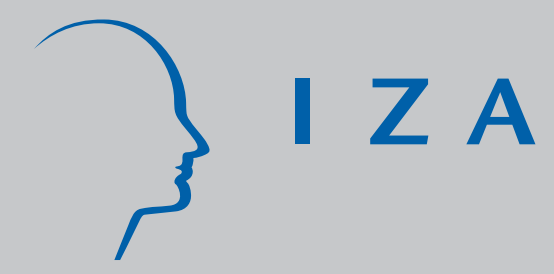

IZADP No. 1531

The Economics of Migrants' Remittances

Hillel Rapoport

Frédéric Docquier

March 2005 


\title{
The Economics of Migrants' Remittances
}

\author{
Hillel Rapoport \\ Bar-llan University, SCID, Stanford University \\ and CADRE, Université de Lille 2 \\ Frédéric Docquier \\ CADRE, Université de Lille 2 \\ and IZA Bonn
}
Discussion Paper No. 1531
March 2005

\author{
IZA \\ P.O. Box 7240 \\ 53072 Bonn \\ Germany \\ Phone: +49-228-3894-0 \\ Fax: +49-228-3894-180 \\ Email: iza@iza.org
}

\begin{abstract}
Any opinions expressed here are those of the author(s) and not those of the institute. Research disseminated by IZA may include views on policy, but the institute itself takes no institutional policy positions.

The Institute for the Study of Labor (IZA) in Bonn is a local and virtual international research center and a place of communication between science, politics and business. IZA is an independent nonprofit company supported by Deutsche Post World Net. The center is associated with the University of Bonn and offers a stimulating research environment through its research networks, research support, and visitors and doctoral programs. IZA engages in (i) original and internationally competitive research in all fields of labor economics, (ii) development of policy concepts, and (iii) dissemination of research
\end{abstract} results and concepts to the interested public.

IZA Discussion Papers often represent preliminary work and are circulated to encourage discussion. Citation of such a paper should account for its provisional character. A revised version may be available directly from the author. 


\section{ABSTRACT}

\section{The Economics of Migrants' Remittances*}

This chapter reviews the recent theoretical and empirical economic literature on migrants' remittances. It is divided between a microeconomic section on the determinants of remittances and a macroeconomic section on their growth effects. At the micro level we first present in a fully harmonized framework the various motivations to remit described so far in the literature. We show that models based on different motives share many common predictions, making it difficult to implement truly discriminative tests in the absence of sufficiently detailed data on migrants and receiving households' characteristics and on the timing of remittances. The results from selected empirical studies show that a mixture of individualistic and familial motives explains the likelihood and size of remittances. At the macro level we first briefly review the standard (Keynesian) and the trade-theoretic literature on the short-run impact of remittances. We then use an endogenous growth framework to describe the growth potential of remittances and present the evidence for different growth channels. We then explore the relationship between remittances and inequality. This relationship appears to be non-monotonic. This is consistent with different theoretical arguments regarding the role of migration networks and/or the dynamics of wealth transmission between successive generations.

JEL Classification: J61, D31, O15

Keywords: remittances, migration, income distribution, private transfer

Corresponding author:

Hillel Rapoport

Department of Economics

Bar-Ilan University

Ramat Gan 52900

Israel

Email: hillel@mail.biu.ac.il

\footnotetext{
* Chapter prepared for the Handbook on the Economics of Reciprocity, Giving and Altruism, ElsevierNorth Holland, forthcoming (Editors: L.-A. Gerard-Varet, S.-C. Kolm and J. Mercier-Ythier). For the most part this chapter was written while Hillel Rapoport was visiting research fellow at the Center for Research on Economic Development and Policy Reform (CREDPR) - now the Stanford Institute for International Development (SCID) at Stanford University's Department of Economics, in 2001-03. He wishes to express his gratitude to Anne Krueger, Nick Hope and Roger Noll, the Center's past, former and current Directors. Cosima Schneider provided excellent research assistance. The study benefited from comments by, and interaction with Flore Gubert, David McKenzie, and Alice Mesnard. Special thanks to Sylvie Lambert for her accurate reading of the preliminary version of this chapter and her many useful comments and suggestions. The usual disclaimer applies.
} 


\section{Outline}

1. Introduction

2. The microeconomics of remittances

2.1. Theory

2.1.1. Altruism

2.1.2. Exchange

2.1.3. A strategic motive

2.1.4. Insurance and moral hazard

2.1.5. Family loan arrangements

2.1.6. Inheritance as an enforcement device

2.1.7 Mixed motives

2.1.8. Summary of predictions

2.2. Evidence

3. The macroeconomics of remittances

3.1. Short-run approaches

3.1.1. The standard macroeconomic view

3.1.2. Trade, relative prices, and welfare

3.2. The long-run view

3.2.1. Liquidity constraints 1 : entrepreneurship

3.2.2. Liquidity constraints 2 : human capital

3.2.3. Migration, remittances and inequality: A dynamic approach

3.3. Evidence on the growth effects of remittances

3.3.1. Migration, remittances and inequality

3.3.2. Remittances and human capital formation

3.3.3. Remittances, return migration and entrepreneurship

3.3.4. Migration, productivity and rural development

4. Conclusion

5. References 


\section{Introduction}

During the last two decades or so, the economic analysis of remittances has experienced a dramatic renewal, applying and sometimes initiating the development of new economic tools and approaches. First of all, the microeconomics of remittances has focused since the early 1980s on the role of information and social interactions in explaining transfer behavior. This resulted in a deep change in the way economists look at the determinants of remittances, with familial and strategic motives being increasingly acknowledged for alongside more traditional motivations. From a more macroeconomic perspective, new growth theories have also profoundly altered the directions for research on the impact of migration and remittances. While previous research in the 1970s and 1980s was centered on the short-run effects of international transfers, mainly within the framework of static trade models, the focus gradually shifted to long-run considerations, notably the role of remittances in the dynamics of inequality and development. In addition, the last period has also seen a substantial upgrading in the econometric tools available for applied research, especially for the analysis of micro data, thus allowing for a renewal of the empirics of remittances as well.

To the best of our knowledge, there is no comprehensive survey on the economic analysis of remittances, at least no recent survey that would cover the new theoretical and empirical findings mentioned above. ${ }^{1}$ These findings provide answers to questions such as: Who transfers? Why? How much? And, most importantly, what are the economic consequences of remittances for developing countries? The answers to the first three questions do not necessarily differ from those exposed elsewhere in this handbook for other types of private transfers. However, the context in which remittances take place, that of developing countries, makes them unique in many respects. First, developing countries are characterized not only by high levels of poverty, but also high levels of inequality and income volatility (which, in turn, make access to credit and insurance so crucial); since remittances have an effect on each of these dimensions, their overall economic impact - and, hence, the marginal value of a dollar of remittances - is likely to be quite large. Second, developing countries are also characterized by pervasive capital markets imperfections, offering no market response to the needs for credit and insurance of the majority of the population;

\footnotetext{
${ }^{1}$ Early descriptive surveys include Russell (1986).
} 
therefore, despite being voluntary and altruistic to a large extent, remittances differ from most private transfers observed in Western countries in that additional motives (insurance, investment, and exchanges of various types of services) are central to explaining transfer behavior. Third, unless exceptions, private transfers in the Western countries either take place "anonymously" — in the sense that donors do not necessarily know the identity of the beneficiaries (e.g., charity, philanthropy) — or within a very restricted familial group; by contrast, remittances are increasingly recognized as informal social arrangements within extended families and communities. Finally, while most public and private transfers tend to reduce economic inequality, this needs not be the case for remittances: the presence of liquidity constraints that impinge investment in migration and education, combined with the use of inheritance procedures to monitor the migrants' behavior, sometimes generate patterns of remittances that tend to increase inter-household inequality.

Another challenging aspect of the study of remittances is related to data collection and analysis. At a macro level, it is not always possible to test appropriately for the macroeconomic impact of remittances because of poor data quality; at a micro level, it is extremely difficult to discriminate between competing theories of remittances, which often share similar predictions as to the impact of the main righthand-side variables, implying that truly discriminative tests have to rely on additional variables for which details are not always available. In spite of these limitations, there is a lot to learn from existing data on remittances. For example, international data reveal that workers' remittances often make a significant contribution to GNP and are a major source of foreign exchange in many developing countries. For some countries, it is not uncommon to observe flows of remittances that equal about half the value of their exports or $10 \%$ of their GDP (see Table 1.1.). This is or was the case for relatively small Caribbean and Pacific countries, but also for traditional laborexporting countries such as Egypt, Turkey, or Pakistan. ${ }^{2}$ In the case of Mexico, it has been estimated that remittances received in 1989 amounted to $10 \%$ of merchandise exports, $65 \%$ of earnings from tourism, were equivalent to agricultural exports, and sufficient to cover three times the balance of payments deficits (Durand et al., 1996); more recently, the Bank of Mexico estimated that Mexican migrants remitted in 1998

\footnotetext{
${ }^{2}$ What is also striking is that in some places remittances are a relatively new phenomenon and are still gaining in magnitude (especially in Central America) while in other places (e.g., Morocco, Turkey), the magnitude of remittances has decreased sharply since the 1970s. See Table 1.1.
} 
about $1.5 \%$ of Mexico's GDP, with remittances reaching as much as $10 \%$ of GDP in one Mexican State (Michoacan). These figures exclude internal (mainly urban-rural) remittances and informal international remittances and are therefore probably well below the actual figures. ${ }^{3}$

Another and perhaps more meaningful way to assess the economic role of remittances is to rely on household surveys and estimate the proportion of households for which remittances are an important source of income. Such surveys tend to show that remittances are often a crucial element of survival and livelihood strategies for many (typically rural) poor households. For example, Rodriguez (1996) reports that $17 \%$ of Philippines' households receive income transfers from abroad, representing $8 \%$ of national income. Similarly, Cox, Eser and Jimenez (1998) found that $25 \%$ of Peruvian households receive private transfers (mainly remittances), representing 22\% of their incomes. On a more reduced scale, de la Brière et al. (2002) show that approximately $40 \%$ of the households in the Dominican Sierra, a poor rural region of the Dominican Republic, have migrant members, $52 \%$ of whom are sending remittances. For El Salvador, Cox Edwards and Ureta (2003) find that 14\% of rural and $15 \%$ of urban households received remittances from friends and relatives abroad in 1997. These studies, as well as many others detailed below, show that remittances are instrumental to achieving mutual insurance, consumption smoothing, and alleviation of liquidity constraints.

As to their economy-wide consequences, it is clear that remittances may have a short-run macroeconomic impact through their effects on price or exchange rate levels. The long run implications of remittances, however, would seem to be more significant. First, remittances impinge on households' decisions in terms of labor supply, investment, education, migration, occupational choice, fertility, etc., with potentially important aggregated effects. Secondly, another channel whereby remittances may affect a country's long-run economic performance is through their distributional effects and impact on economic inequality, a key issue from an

\footnotetext{
${ }^{3}$ The number of internal migrants itself is unknown. To give a very crude element of comparison, the number of international migrants in 1981 was estimated at 95 millions, whereas India alone had about 200 millions internal migrants for that same year (Zlotnik, 1998). See Lucas (1997) for a survey of economic research on internal migration in developing countries. Russell (1986) suggested that official international flows of remittances account for less than half of the total amount (internal and informal remittances included) actually remitted. Note also that official statistics exclude small transfers (moreover, the thresholds above which bank transfers are reported differ from country to country), but also transfers in-kind, transfers directly carried by the migrants themselves, and unofficial transfers (which are likely to be substantial where there is a high black-market premium on foreign exchange).
} 
endogenous growth perspective. Once we know that the amounts at stake are important and their potential economic impact is significant, it is worth trying to understand the determinants of remittances. This is the purpose of Section II on the size and motives of remittances. Section III details the macroeconomic consequences of remittances, and distinguishes between short-run and long-run effects. Section IV offers concluding remarks.

Table 1.1: International remittances as a share of exports and GDP

(Selected countries and years, in \%)

\begin{tabular}{|l|r|r|r|r|r|r|r|r|}
\hline \multirow{2}{*}{$\begin{array}{l}\text { Selected } \\
\text { Countries }\end{array}$} & \multicolumn{2}{|c|}{1980} & \multicolumn{2}{|c|}{1990} & \multicolumn{2}{|c|}{1995} & \multicolumn{2}{|c|}{1999} \\
\cline { 2 - 9 } & Exports & GDP & Exports & GDP & Exports & GDP & Exports & \multicolumn{1}{c|}{ GDP } \\
\hline Albania & & & & & 127.2 & 15.5 & 85.1 & 9.7 \\
\hline Bangladia & 2.8 & 1.0 & 2.4 & 0.6 & 9.7 & 2.7 & 7.1 & 2.0 \\
\hline Benin & 27.0 & 1.1 & 40.4 & 2.5 & 28.9 & 3.2 & 28.1 & 3.7 \\
\hline Burkina & 34.7 & 5.5 & 33.7 & 4.8 & 22.8 & 4.6 & 18.4 & 3.1 \\
\hline CapeVerde & 87.1 & 8.8 & 39.7 & 5.1 & 29.0 & 3.8 & 22.9 & 2.6 \\
\hline Comoros & 15.1 & 1.3 & 27.9 & 4.0 & 26.7 & 5.7 & 24.4 & 6.4 \\
\hline Dominic. $\mathrm{R}$ & 14.4 & 2.8 & 13.2 & 4.5 & 21.5 & 6.7 & 28.7 & 8.7 \\
\hline Ecuador & & & 1.4 & 0.5 & 3.2 & 0.9 & 15.4 & 5.7 \\
\hline Egypt & 38.6 & 11.8 & 43.3 & 8.7 & 24.3 & 5.5 & 26.4 & 4.2 \\
\hline El Salvador & 0.9 & 0.3 & 40.1 & 7.4 & 51.6 & 11.2 & 44.5 & 11.0 \\
\hline Eritrea & & & & & 69.4 & 20.7 & 194.1 & 19.7 \\
\hline Guatemala & & & 6.6 & 1.4 & 12.8 & 2.4 & 13.4 & 2.6 \\
\hline Honduras & & & 4.5 & 1.6 & 6.9 & 3.0 & 13.8 & 5.9 \\
\hline India & 24.7 & 1.5 & 7.2 & 0.5 & 18.1 & 2.0 & 21.3 & 2.6 \\
\hline Jamaica & 3.7 & 1.9 & 6.2 & 3.2 & 23.0 & 12.7 & 20.2 & 9.9 \\
\hline Jordan & 37.7 & 15.0 & 20.1 & 12.4 & 35.7 & 18.3 & 47.3 & 20.6 \\
\hline Lebanon & & & 355.7 & 64.0 & 182.9 & 21.5 & & \\
\hline Mali & 22.6 & 3.3 & 25.8 & 4.4 & 21.5 & 4.5 & 13.1 & 3.3 \\
\hline Morocco & 32.2 & 5.6 & 29.4 & 7.8 & 21.8 & 6.0 & 18.4 & 5.5 \\
\hline Nepal & 13.3 & 1.5 & 16.0 & 1.7 & 9.5 & 2.3 & 13.2 & 3.0 \\
\hline Nicaragua & & & & & 11.2 & 4.0 & 39.3 & 13.2 \\
\hline Pakistan & 59.1 & 7.4 & 31.2 & 4.9 & 19.1 & 3.1 & 12.0 & 1.8 \\
\hline Samoa & 66.8 & 16.7 & 96.2 & 29.4 & & 25.3 & & 25.3 \\
\hline Sri Lanka & 11.7 & 3.8 & 16.5 & 5.0 & 17.3 & 6.2 & 18.8 & 6.6 \\
\hline Turkey & 58.3 & 3.0 & 16.2 & 2.2 & 9.8 & 2.0 & 10.5 & 2.4 \\
\hline Yemen, R. & & & 195.5 & 32.2 & 82.3 & 26.9 & 46.9 & 18.1 \\
\hline Source: & & & & & & &
\end{tabular}

Source: World Bank (2001). 


\section{The microeconomics of remittances}

Is the study of remittances in essence distinct from that of migration? More precisely, may remittance behavior, for the most part, be predicted by the migrants' characteristics, or is there something beyond that, thus justifying a separated treatment? To answer this question, we refer to Edward Funkhouser's (1995) comparative study on remittances to the capital cities of El Salvador and Nicaragua. In this study, Funkhouser noted that while the number of migrants and the general economic conditions prevailing in the two countries during the 1980 s were quite similar, twice as many households received remittances from relatives abroad in San Salvador than in Managua; moreover, for those who received remittances, the average transfer received in San Salvador was twice as high as that in Managua. To explain this apparent puzzle, two possible directions may be suggested: is it that migrants selfselect differently in the two countries? Or is it that, among those who emigrated, "remitters" self-select differently?

Using micro data on both migrants and receiving households, Funkhouser (1995) concluded in favor of the latter explanation. Indeed, the data revealed many similarities between the two pools of migrants with respect to age, education, gender, and, to a lesser extent, number of years since emigration. ${ }^{4}$ In other words, differences in remitting behavior could not be accounted for by differences in households' or migrants' observed characteristics, including the timing of migration. By contrast, the estimation of remittance functions revealed substantial differences in remitting behavior between the two samples, allowing to conclude that differences in unobserved characteristics (i.e., how remitters self-select with the pool of migrants) are central to explaining inter-country differences in remittance behavior. Two insights from Funkhouser's study tend to confirm that this is indeed the case. First, remitters were negatively selected out of the pool of emigrants, but in a more pronounced way for Nicaragua, meaning that educated Salvadorans tend to be less detached from their family and/or more "patriotic" (for whatever reason). Secondly, it was striking that while in El Salvador, the likelihood and level of remittances reacted

\footnotetext{
${ }^{4}$ For both countries, neither gender nor age were significantly correlated with the probability or level of remittances, education decreased the likelihood of remittances but increased the amount remitted conditional on remitting, and both the likelihood and level of remittances were positively affected by "proximity" (blood or marriage relations). Funkhouser (1995) used probit estimates of the probability of remittances and a linear functional form for the estimation of the remittance function, while selfselection was accounted for using a Heckman-type two-stage procedure.
} 
ambiguously to the time spent in the USA (negatively for non-family members, and positively for close family members), they were negatively correlated to years since emigration for both immediate family members and other relative emigrants in Nicaragua, suggesting higher propensities to return among Salvadorans.

Of course, such behavioral differences may simply be due to the different political contexts prevailing in the two countries and the "repulsive" effect the Sandinist government may have had on wealthy Nicaraguans emigrants. Still, Funkhouser's (1995) study remains exemplary in that it highlights that migration and remittance decisions, although interdependent, are generally influenced by different sets of determinants. In other words, remittance behavior is not simply predicted by the migrants' characteristics, and its analysis requires specific attention. In particular, the "behavioral differences" put forward by Funkhouser are nothing but another wording for different motivations to remit.

Obviously, the most common motivation to remit is simply that migrants care of those left behind: spouses, children, parents, and members of larger kinship and social circles. Until recently, however, this altruistic inclination to remit was more frequently assumed than tested against competing theories. Alongside altruism, and notwithstanding self-rewarding emotions associated with remitting behavior (e.g., warm-glow), the very fact that donors and beneficiaries of remittances are spatially differentiated creates room for the expression of additional motives. First of all, remittances may just "buy" a wide range of services such as taking care of the migrant's assets and relatives at home, with the likelihood and size of remittances depending on whether and when the migrant intends to return. Secondly, it is clear that migration is primarily (but not only) driven by wage differentials, implying that people are ready to incur substantial moving costs in order to access to international migration. Such migration costs, however, are beyond the possibilities of many prospective migrants and, given capital markets imperfections, must be financed through informal family loans repaid later (with interest) in the form of remittances. Even when wage differentials are not significant enough to compensate for migration costs, it may still be optimal for some families to have migrant members. This is the case, in particular, for rural households whose agricultural income is highly volatile due to changing climatic conditions and other idiosyncratic risks. When the market does not allow for a trade-off between a lower mean and a reduced variance, migration by some members may become a straightforward way to achieve mutual 
insurance; for this to occur, wages at destination need not be higher providing that incomes at home and destination are not positively correlated.

Migration is now recognized as an informal familial arrangement, with benefits in the realms of risk-diversification, consumption smoothing, and intergenerational financing of investments, and remittances are a central element of such implicit contracts. The small number of members, however, limits the size of the insurance pool and the degree of risk diversification that can be attained. This is somehow compensated by families' comparative advantage in obtaining reliable information on individual members (their skills, degree of trustworthiness, etc.), and their enforcement power. Should intrafamilial altruism be insufficient to make the contract self-enforcing, families may sanction opportunistic behavior through inheritance procedures and social sanctions. Despite these informational and enforcement advantages, familial arrangements are not immune to strategic behavior: distance renders the migrants' resources - and the needs of the family - imperfectly observable, thus creating informational problems that are more pervasive - and, therefore, make strategic behavior more likely - than in many other transfer situations.

As we shall see, remittances combine an altruistic component, a repayment-ofloans component, an insurance component, an inheritance component, and exchange of a variety of services, this complex mixture of motives being best described using fuzzy concepts such as "impure altruism" (Andreoni, 1989) or "enlightened selfishness" (Lucas and Stark, 1985). However, it is extremely difficult to empirically discriminate between these different motives: most empirical studies regress remittances on a set of variables (which typically includes pre-transfer incomes of both senders and recipients), but any sign for these relations may be interpreted in a number of ways, and the additional information needed to implement more discriminative tests (e.g., longitudinal data on the timing of remittances, information on the migrant's education, the recipient household's assets and number of heirs, etc.) is rarely available in a sufficiently detailed manner.

These two characteristics of the microeconomics of remittances - coexistence, at the theoretical level, of a variety of motives that are not exclusive one of the other, and, at the empirical level, difficulties inherent to the implementation of truly discriminative tests - provide the structure for this section. We first present the different motivations to remit suggested so far in the literature in a unified theoretical framework, with an emphasis on their testable implications so as to contrast them, 
when possible, by their predictions (2.1). We then review the evidence from selected empirical studies (2.2).

\subsection{Theory}

To keep the general model as simple as possible, and unless specified differently, we consider only two decision units: one migrant $(m)$, and one recipient household $(h)$, which can consist of one or more individuals. Utility is denoted by $U$, pre-transfer incomes by $I$, consumption by $C$, and $T$ stands for the amount remitted by $m$ to $h$. Additional variables will be introduced gradually.

\subsubsection{Altruism}

To present the altruistic motive, we borrow from Stark (1995, Chapter 1) a model that is convenient to account for both unilateral and mutual (or two-sided) altruism. Each agent's utility $U^{i}, i=m, h$, is assumed to be affected by the felicity (or ophelimity) derived from his or her own consumption, $V\left(C^{i}\right)$, with $V^{\prime}>0$ and $V^{\prime \prime}<0$, and the utility of the other. Utility may be expressed as a weighted average of these two elements, with $0 \leq \beta^{i} \leq 1 / 2$ denoting the individual's degree of altruism:

$$
\begin{aligned}
& U^{m}\left(C^{m}, C^{h}\right)=\left(1-\beta^{m}\right) V^{m}\left(C^{m}\right)+\beta^{m} U^{h}\left(C^{h}, C^{m}\right) \\
& U^{h}\left(C^{h}, C^{m}\right)=\left(1-\beta^{h}\right) V^{h}\left(C^{h}\right)+\beta^{h} U^{m}\left(C^{m}, C^{h}\right)
\end{aligned}
$$

Solving these two equations in terms of $V\left(C^{i}\right)$ gives:

$$
\begin{aligned}
& U^{m}\left(C^{m}, C^{h}\right)=\left(1-\gamma^{m}\right) V\left(C^{m}\right)+\gamma^{m} V\left(C^{h}\right) \\
& U^{h}\left(C^{h}, C^{m}\right)=\left(1-\gamma^{h}\right) V\left(C^{h}\right)+\gamma^{h} V^{m}\left(C^{m}\right)
\end{aligned}
$$

where

$$
0 \leq \gamma^{m}=\frac{\beta^{m}\left(1-\beta^{h}\right)}{1-\beta^{m} \beta^{h}} \leq 1 / 2 \text { and } 0 \leq \gamma^{h}=\frac{\beta^{h}\left(1-\beta^{m}\right)}{1-\beta^{m} \beta^{h}} \leq 1 / 2 .
$$

The migrant's utility function may thus be rewritten as:

$$
U^{m}\left(C^{m}, C^{h}\right)=\left(1-\gamma^{m}\right) V\left(I^{m}-T\right)+\gamma^{m} V\left(I^{h}+T\right)
$$

Maximizing (2.5) with respect to $T$ gives the first order condition:

$$
-\left(1-\gamma^{m}\right) \frac{\partial V}{\partial C^{m}}+\gamma^{m} \frac{\partial V}{\partial C^{h}} \leq 0, \text { with equality for } \mathrm{T}>0 .
$$

Ruling out the possibility of negative transfers from $m$ to $h$, and with $V()=.\ln ($.$) , it is straightforward to see that the optimal remittance is given by:$ 


$$
T^{*}=\operatorname{Max}\left\{\gamma^{m} I^{m}-\left(1-\gamma^{m}\right) I^{h}, 0\right\}
$$

with $\partial T^{*} / \partial I^{m}>0, \partial T^{*} / \partial I^{h}<0, \partial T^{*} / \partial \beta^{m}>0$, and $\partial T^{*} / \partial \beta^{h}<0$.

That is, the altruistic transfer increases with the migrant's income and degree of altruism, and decreases with the recipient's income and, more interestingly, degree of altruism. Since the altruistic parameters $\beta^{m}$ and $\beta^{h}$ are not observable, and that other possible motives predict that the amount transferred would increase with the migrant's income, as we shall see, the main testable implication of the altruistic model is that transfers cannot increase with the recipient's income. This is by contrast to other motives, as will be detailed below. Another interesting prediction of the pure altruism hypothesis is that an increase by one dollar in the income of the migrant, coupled with a one-dollar drop in the recipient household's income, should raise the amount transferred exactly by one dollar. Formally, the transfer-income derivatives should satisfy the following condition:

$$
\frac{\partial T}{\partial I^{m}}-\frac{\partial T}{\partial I^{h}}=1
$$

An important implication of this is that the distribution of consumption should be independent of the distribution of income; this is a very strong testable implication of the altruistic motive, rarely confirmed in empirical studies (see section 2.2. below).

As already mentioned, the altruistic motive for remittances has been more commonly assumed than contrasted to other possibilities. To illustrate this, we again refer to Funkhouser (1995), who proposed a behavioral model of remittances based on altruism, with the following testable implications:

(a) emigrants with higher earnings potential remit more;

(b) low-income households receive more;

(c) remittances should increase with both the degree of proximity between the migrant and the remaining household members and the migrant's intentions to return;

(d) remittances by a given migrant should decrease with the number of other emigrants from the same household;

\footnotetext{
${ }^{5}$ This is the classical result where, since $m$ knows that $h$, being altruistic towards him, is harmed when $m$ 's income is decreased, there are less transfers under mutual than unilateral altruism (in other words, the less altruistic is $h$ towards $m$, the more he receives).
} 
(e) the time profile of remittances should depend on the comparison between the migrants' time-discount factor and their earnings profile abroad.

As the discussions below will show, predictions (a) and (b) are compatible with a number of other possible motives, predictions (c) and (e) are extremely general, while prediction (d) is consistent with the investment hypothesis, the altruistic hypothesis and the inheritance hypothesis.

\subsubsection{Exchange}

There are many situations of pareto-improving exchanges involving remittances. The most natural way to think of such situations is to assume that remittances simply "buy" various types of services such as taking care of the migrant's assets (e.g., land, cattle) or relatives (children, elderly parents) at home. Such motivations are generally the sign of a temporary migration, and signal the migrants' intention to return. Another intuitive way to think of such exchanges is to consider the case where, due to market imperfections, transaction costs may be saved on through non-market interpersonal agreements. For example, migrants' remittances may be viewed as repayments of loans used to finance the migrant's investments in human capital or the expenditures incurred in the course of migration (we will analyze this particular type of intertemporal exchanges in Section 2.1.5. on the "investment" motive). In such exchanges, there is a participation constraint determined by each partner's external options, with the exact division of the pie (or surplus) to be shared depending on their bargaining power. For example, when remittances buy services such as taking care of the migrant's assets or relatives, it is clear that the amount transferred must lie somewhere between the market price for such services (or their marginal value for the buyer if these are not traded) and the opportunity cost of the recipient. As to the partners' respective bargaining powers, these may be determined by local labor markets conditions (e.g., more unemployment raises the migrant's bargaining power). Similarly, the implicit interest rate for the repayment of loans must lie somewhere between the market rate for debtors and creditors. ${ }^{6}$

In the following we use an exposition of the exchange motive based on Cox (1987), which we adapt by considering the case of non-altruistic agents only and a fixed amount of service. Assume that remittances buy a fixed quantity of service $\bar{X}$. 
The sides' utility functions are now given by $V^{i}\left(C^{i}, \bar{X}\right), i=m, h$, with $V_{\bar{X}}^{m^{\prime}}>0$, $V_{\bar{X}}^{h^{\prime}}<0$ and $V_{\bar{X}}^{m^{\prime \prime}}<0, V_{\bar{X}}^{h^{\prime \prime}}>0$ to account for the increasing disutility of effort.

Suppose that the surplus is entirely appropriated by the migrant, who transfers the minimal compensation required for the service to be provided. ${ }^{7}$ It follows that the remaining resident would accept to provide the service would the compensating transfer be such that:

$$
V^{h}\left(I^{h}+T, \bar{X}\right) \geq V^{h}\left(I^{h}, 0\right)
$$

Solving this participation constraint for equality, $T$ may be expressed as: $T=T\left(\bar{X}, I^{h}\right)$. Then, the implicit function theorem gives:

$$
\begin{gathered}
\frac{\partial T}{\partial I^{h}}=-\frac{\left.\partial V^{h}\left(I^{h}+T, \bar{X}\right) / \partial C^{h}-\partial V^{h}\left(I^{h}, 0\right) / \partial C^{h}\right)}{\partial V^{h}\left(I^{h}+T, \bar{X}\right) / \partial C^{h}}<0 \\
\frac{\partial T}{\partial \bar{X}}=-\frac{\partial V^{h}\left(I^{h}+T, \bar{X}\right) / \partial \bar{X}}{\partial V^{h}\left(I^{h}+T, \bar{X}\right) / \partial C^{h}}>0 .
\end{gathered}
$$

This shows that the amount transferred increases with the quantity of service to be offered but reacts ambiguously to an exogenous increase in the recipient's pretransfer income. Indeed, the sign of $\partial T / \partial I^{h}$ depends on the effect of $X$ on the marginal utility of consumption. Intuitively, if $X$ has no effect on the marginal utility of income (as is the case, for example, for an additive and separable utility function), this is higher at $T$ equal zero than at $T$ positive; then, the sign of the numerator is negative and the sign of the derivative is positive. However, if there exists some complementarities between $X$ and $I$, the opposite may hold so that a negative sign for the derivative is also consistent with the exchange hypothesis.

Note that a similar participation constraint could be derived for the migrant, the maximal amount he would accept to transfer being such that: $V^{m}\left(I^{m}-T^{\max } ; \bar{X}\right)=V^{m}\left(I^{m} ; 0\right)$. Applying the same techniques as above, it could be shown that this maximal transfer increases with the migrant's income. The central

\footnotetext{
${ }^{6}$ Since the difference between the two is a possible measure of the degree of market imperfection, one conceives that such exchanges are more likely in the context of developing countries.

${ }^{7}$ A more general (but more complex) model with egoistic agents (e.g., Cox, Eser and Jimenez, 1998) would allow for different possible divisions of the pie. However, we neglect this aspect as it does not affect the central predictions of the exchange model.
} 
prediction of the exchange model, therefore, is that in contrast to the altruistic model, an increase in the recipient's income may raise the amount transferred. ${ }^{8}$

To be operating, however, the exchange motive requires the recipient's minimal compensation to be lower than the maximal amount the migrant is ready to offer: $T<T^{\max }$. Hence, another interesting difference in the predictions between the altruistic and the exchange motives concerns the likelihood of remittances: as shown by Cox, Eser and Jimenz (1998), in the altruistic case, the probability of transfer decreases with recipients' incomes, meaning that the effects of an increase in the recipient's income on the likelihood of transfers, on the one hand, and the amount transferred, on the other hand, are of identical signs. However, since this needs not be the case for the exchange motive, this introduces a supplementary difference in the predictions of the two models: while in the altruistic case, the probability for a given household to receive a transfer should be positively correlated to the average amount received, inverse correlations between these two variables could be the sign that an exchange motivation is at work.

The two models may be further contrasted; in particular, as mentioned above, a more general exchange model would allow for different possible contractual arrangements reflecting the parties' bargaining powers. In such a setting, higher unemployment at home should affect negatively the transfer received (since the recipient's bargaining power is thereby decreased), while the unemployment rate should not affect remittances received by a given household when altruism applies. More generally, the exchange model - especially its bargaining version - implies that threat-points matter. Hence, an interesting policy-implication of this approach is that, contrarily to the neutralization of public redistribution that is known to characterize altruism, in the case of exchange-motivated transfers, it may well be that public transfers, instead of crowding out private transfers, induce an increase in the amounts

${ }^{8}$ This is best shown using a logarithmic example: $V^{h}\left(C^{h}, \bar{X}\right)=\ln C^{h}+\ln (a-\bar{X})$. In this case, the household participation constraint becomes: $\ln \left(I^{h}+T\right)+\ln (a-X)=\ln I^{h}+\ln a$, so that the minimal compensating transfer is given by: $T=\frac{\bar{X}}{a-\bar{X}} I^{h}$, showing that the amount remitted is proportional to the recipient's income. 
privately received by the recipients of public transfers (since their bargaining power is thereby increased). ${ }^{9}$

Until now, we have considered situations without information imperfections. In the real world, various types of informational asymmetries may arise in the context of migration. A first imperfection concerns the way employers at destination evaluate the migrants' productivity. Since individual skills are imperfectly observable, it may be that, during a given period, the migrants' wage is fixed according to a crude evaluation of their average productivity. To the extent that the migrants' may influence these beliefs, remittances may be used strategically and aim at positive selection among migrants. A second imperfection concerns the fact that, once the migrant is abroad, an informational asymmetry is created in favor of the non-migrants with respect to the economic conditions at home. Since remittances provide those left behind with an insurance against bad economic times, such informational asymmetries may also give rise to moral hazard.

\subsubsection{A strategic motive for remittances}

By contrast to the first two motives just exposed, the "strategic" motive is specific to the context of migration where it has first been developed (Stark, 1995, Chapter 4). As underlined above, remittances may be both the cause and the consequence of migration; therefore, it is necessary to treat those two interdependent decisions in an encompassing framework. Among various plausible comprehensive approaches, Stark suggested that remittances may be part of a strategic interaction aiming at positive selection among migrants. The rationale is approximately the following: when migrants are heterogeneous in skills and individual productivity is not perfectly observable on the labor market of the host country (at least for a given period of time), employers apply statistical discrimination so that migrant workers are paid the average productivity of the minority group to which they belong. In such a context, there is room for cooperative arrangements between skilled and unskilled migrants: the former can act cohesively and "bribe" the latter in order to maintain them home; in addition, the community of those left behind must also control potential free riders (since any given unskilled worker would have a strong incentive to be the first to emigrate once positive selection is achieved).

\footnotetext{
${ }^{9}$ On this possibility, see Cox and Jimenez (1992) and Cox, Eser and Jimenz (1998).
} 
To illustrate this, consider the case where $m$ and $h$ are potential migrants but $h$ is less skilled than $m$. More precisely, assume that $h$ 's productivity is only a proportion $\pi, 0<\pi<1$, of $m$ 's productivity. If both remain home, there is no information problem: $h$ earns $I^{h}$ and $m$ earns a higher wage, $\frac{I^{h}}{\pi}$. If $m$ alone emigrates, she is paid her marginal product in the destination country, $I^{m}$. If both $h$ and $m$ migrate, however, they are paid according to their average productivity, $\frac{1+\pi}{2} I^{m}$, at least until individual skills are revealed. This is best summarized using the following payoff matrix:

Player $h$

\begin{tabular}{|c|c|c|c|}
\hline \multirow{3}{*}{ Player $m$} & & Migrate & Not Migrate \\
\hline & Migrate & $\left(\frac{1+\pi}{2} I^{m}, \frac{1+\pi}{2} I^{m}\right)$ & $\left(I^{m}, I^{h}\right)$ \\
\hline & Not Migrate & $\left(\frac{I^{h}}{\pi}, \pi I^{m}\right)$ & $\left(\frac{I^{h}}{\pi}, I^{h}\right)$ \\
\hline
\end{tabular}

Formally, the strategic motive operates when two conditions hold. First, in the game without transfers, (Migrate, Migrate) must be a Nash equilibrium. This requires:

$$
\frac{1+\pi}{2} I^{m}>\frac{I^{h}}{\pi}
$$

Second, assuming that condition (2.13) holds, strategic remittances must make both players better off. For this to hold true, we must have simultaneously:

$$
I^{m}-T \geq \frac{1+\pi}{2} I^{m}
$$

and

$$
I^{h}+T \geq \frac{1+\pi}{2} I^{m}
$$

with strict inequality for at least one of the two players.

From (2.15), and consistently with our presentation of the exchange motive, one may derive the minimal optimal transfer:

$$
T^{*}=\frac{1+\pi}{2} I^{m}-I^{h}
$$


Substituting (2.16) into (2.14) gives:

$$
I^{h}>\pi I^{m}
$$

meaning that efficiency may be achieved through side-payments if and only if unskilled workers have no interest in emigration unless they are pooled with skilled workers. Under the above conditions, remittances may be effective in achieving positive selection, and should be viewed as side-payments taking place in the course of a strategic interaction between migrants and non-migrants.

Before we turn to the predictions of this model, we would like to point out some of its potential weaknesses, such as the tendency for each migrant to free ride on others' efforts to achieve positive selection, and the low gains at stake when the revelation of individuals' skills does not take too long. ${ }^{10}$ In addition, Docquier and Rapoport (1998) suggested that this theory requires from the employers at destination a "knowledge in anthropology" that they are unlikely to possess. Indeed, information on group affiliations is not shared symmetrically between employers and migrant workers. The former can associate a given community of migrants to a wider group of foreigners; the result would be that the selection undertaken by one particular group would benefit the whole group it is identified with. For example, if the Mossi from Burkina Faso who are working, say, in France, are successful in preventing the migration of their unskilled brothers but that, at the same time, French employers do observe the average productivity of the African people altogether, strategic transfers will definitely not be a sustainable means for promoting wealth among the Mossi.

Notwithstanding the different arguments above, the strategic motive hypothesis generates a number of interesting predictions listed by Stark (1995: 97-99) as follows: "First, [..], migration will be selective right from the start. [..] Selectivity and remittances are positively related. [..] Second, remittances will be targeted to those at home who have earning power since there would be no need to "bribe" those who would not credibly threaten to engage in labour migration. [... Fourth, remittances come to an end once the high-quality workers are identified. [..] Fifth, the formation of groups is more likely when the [intercountry] differential in wage is large". More formally, from (2.16), it is straightforward to see that, as in the case of altruistic transfers, the level of remittances is expected to rise with the migrant's pre-

\footnotetext{
10 Assessing a "high-productivity reputation" among Philippine's nurses or among Bangladeshi
} construction workers in the Gulf countries have been suggested as possible illustrations for this 
transfer income and to decline with the recipients' pre-transfer income $\left(\partial T^{*} / \partial I^{m}=(1+\pi) / 2>0, \partial T^{*} / \partial I^{h}=-1<0\right)$. However, by contrast to the altruistic case, it is clear that the strategic motive predicts a stronger transfer response to pretransfer income inequality, given that:

$$
\frac{\partial T}{\partial I^{m}}-\frac{\partial T}{\partial I^{h}}=\frac{3+\pi}{2}>1
$$

According to Stark, therefore, the omission of the strategic motive for remittances could be the reason why the degree of altruism inferred from empirical studies is generally biased upward. However, the relevancy of the theory is difficult to assess: some of its predictions are similar to those of the altruistic model (e.g., selectivity and remittances are also positively related when altruism prevails; furthermore, selectivity may be obtained as a byproduct of altruistic transfers - see section 2.1.7. below) or are not easily testable (e.g., recipient households are themselves composed of heterogeneous individuals and even if targeting towards members who are both low-skill and potential migrants would take place, it would hardly be observable). Indeed, we are not aware of an empirical study specifically designed to test for the presence of a strategic motive for remittances.

Until now, we have considered migration and remittances as individual decisions; another fruitful possibility is to think of migration and remittances as resulting from social and familial interactions. Notably, in a context of imperfect capital markets, remittances may be part of an implicit migration contract between the migrant and his or her family, allowing the familial entity to access to higher and/or less volatile incomes.

\subsubsection{Insurance and moral hazard}

"There are six important environmental and technological characteristics of many rural areas in low-income countries that must be incorporated in any useful analysis of institutions in such settings: a) an important production input (weather) is stochastic, its realization during the course of production being unpredictable and exogenous; $b$ ) the intertemporal distribution of weather outcomes is characterized by stationarity; c) positive correlations in weather outcomes diminish with distance; d) another

strategic motive; in these examples, the free rider problem is solved by governmental control over the whole emigration process. 
important production input, land, is immobile; e) the technology of production is stable; f) and costs of acquiring information are high” (Rosenzweig, 1988a, p. 1150). Such characteristics make income volatility a salient attribute of agriculture in the rural regions of most developing countries; in the quasi-absence of credit and insurance markets, this gives rise to a variety of informal inter- and intrafamilial coinsurance arrangements. Interfamilial arrangements include traditional manifestations of reciprocity between producers of a given village, with cooperation emerging from their repeated interactions (Coate and Ravallion, 1993, Fafchamps, 1992). As to intrafamilial arrangements, and given the characteristic c) above, these often imply allocating some members outside of agriculture, via urban or foreign migration (Stark and Levhari, 1982, Rozenzweig, 1988a and 1988b, Lambert, 1994, Chen and Chiang, 1998). ${ }^{11}$

Urban and foreign jobs are generally subject to risks uncorrelated with those impeding on agricultural activities at home (e.g., crop failure, cattle disease, etc.). Hence, migrants would insure the remaining members of the family against drops in rural incomes, and receive assistance in case of unemployment or for retirement, with the exact terms of the insurance contract depending on the relative bargaining power of the sides. To be operating, however, such pareto-improving arrangements must also be self-enforcing. This is generally achieved because a sufficient degree of altruism prevails within the family, or, more prosaically, because families detain reliable information on individuals' types and, thus, may be "picky" in selecting the right migrants (i.e., those who combine high income potentials and degrees of loyalty). ${ }^{12}$ Should this not be sufficient, families can ultimately sanction opportunistic behavior using a variety of retaliation strategies. Alongside reputation (loss of prestige), or ostracism, default to remit may also be sanctioned by denying the migrant rights to future family solidarity (this is the "mutual" aspect of the contract), inheritance, or return to the village for retirement, an option that most migrants want to keep open. This also implies that, ceteris paribus, rich families that can monitor the migrants' behavior through inheritance procedures would tend to rely on migration more than

\footnotetext{
11 Another possibility is to allocate members in (sufficiently) distant villages through intra-rural migration and marriage (Rosenzweig and Stark, 1989).

12 This could account for the fact that it is not always the members with the highest wage potential that are sent, but sometimes those considered as providing more secure sources of remittances. This is the argument raised by Lauby and Stark (1988) to explain the higher migration propensities of daughters in the context of rural-urban migration in the Philippines.
} 
poor families (Hoddinott, 1994). We discuss the role of inheritance in more details in section 2.1.6 below.

For the sake of simplicity, we neglect hereafter the insurance provided by the family to the migrant in case of economic "failure" of the latter. The risks that impinge on urban (or foreign) activities are kept implicit; would these materialize, it is simply assumed that the migrant would be delivered from his obligation to remit. However, reverse transfers may be observed in "good rural times" in some conditions. Besides, the insurance described below is not perfect since the volatility of familial income, although decreased, remains positive.

Consider a family with two members living for two periods. Each member receives a given first-period wage, $I^{0}$, and the second-period rural wage is random, amounting to $\underline{I}^{h}$ with probability $p$ and $\bar{I}^{h}$ with probability $1-p$, and $\underline{I}^{h}<\bar{I}^{h}$. This is an aggregate uncertainty, which affects all individuals in the same way. The utility function is identical for all agents and is additively separable. Agents' expected utility is therefore given by:

$$
E\left(V^{0}\right)=v\left(I^{0}\right)+p v\left(\underline{I}^{h}\right)+(1-p) v\left(\bar{I}^{h}\right)
$$

with $v^{\prime}>0$ and $v^{\prime \prime}<0$ to account for risk-aversion.

Suppose now that agents have the possibility to migrate to a destination where there is no uncertainty, and earn a wage $I^{m}$ during the second period. Migration is costly and implies financing a fixed migration cost $(c)$ at the beginning of the second period. Assume moreover than all agents are credit constrained, so that no individual member is able to finance the migration cost alone, meaning that migration requires a familial arrangement:

$$
I^{0}<c<2 I^{0}
$$

During the first period, agents may agree on an informal contract specifying how migration costs are shared and the amounts to be remitted in bad and good states of nature. The set of Pareto-efficient contracts is given by:

$$
\underset{\xi, T_{p}, T_{1-p}}{\operatorname{Max}} E\left(V^{m}\right)+\lambda\left[E\left(V^{h}\right)-\bar{V}^{h}\right]
$$

where $T_{p}$ and $T_{1-p}$ are the amounts to be remitted in the bad and the good state, respectively, $\xi$ is the share of the migration cost supported by the migrant, $\lambda$ is the 
relative weight of the remaining agent in the bargaining process, $\bar{V}_{h}$ is a given utility level for $h$, and $E\left(V^{m}\right)$ and $E\left(V^{h}\right)$ denote the expected levels of utility for the migrant and the remaining household, respectively, with:

$$
\begin{aligned}
& E\left(V^{m}\right)=v\left(I^{0}-\xi c\right)+p v\left(I^{m}-T_{p}\right)+(1-p) v\left(I^{m}-T_{1-p}\right) \\
& E\left(V^{h}\right)=v\left(I^{0}-(1-\xi) c\right)+p v\left(\underline{I}^{h}+T_{p}\right)+(1-p) v\left(\bar{I}^{h}+T_{1-p}\right)
\end{aligned}
$$

The first order conditions are given by: ${ }^{14}$

$$
\begin{aligned}
& -c v^{\prime}\left(I^{0}-\xi c\right)+\lambda c v^{\prime}\left(I^{0}-(1-\xi) c\right)=0 \\
& -p v^{\prime}\left(I^{m}-T_{p}\right)+\lambda p v^{\prime}\left(\underline{I}^{h}+T_{p}\right)=0 \\
& -(1-p) v^{\prime}\left(I^{m}-T_{1-p}\right)+\lambda(1-p) v^{\prime}\left(\bar{I}^{h}+T_{1-p}\right)=0
\end{aligned}
$$

To illustrate this interaction, we assume that $\lambda=1$ and $I^{m}=E\left(I^{h}\right)$. In this simple case, $\xi^{*}=1 / 2$, migration reduces uncertainty by one half, and expected utilities are equalized. Migration is worthy, however, only if migration costs are sufficiently low, i.e., below a critical threshold $c^{*}$ that depends on the degree of riskaversion. This is apparent from Figure 2.1., where migration reduces uncertainty by one-half, generating a gain in utility that exactly compensates for the migration cost incurred in the first period.

${ }^{13}$ Note that while $T_{p}$ is necessarily positive, $T_{1-p}$ can in principle take any sign.

${ }^{14}$ Using a simple utility function such as $v()=.\ln ($.$) gives the following solutions:$

$\xi^{*}=\frac{(\lambda-1) I^{0}+c}{(\lambda+1) c} ; T_{p}^{*}=\frac{\lambda I^{m}-\underline{I}^{h}}{\lambda+1} ; T_{1-p}^{*}=\frac{\lambda I^{m}-\bar{I}^{h}}{\lambda+1}$. Substituting these solutions into (2.20) gives:

$E\left(V^{m}\right)=\ln \left(\frac{2 I^{0}-c}{\lambda+1}\right)+p \ln \left(\frac{I^{m}+\underline{I}^{h}}{\lambda+1}\right)+(1-p) \ln \left(\frac{I^{m}+\bar{I}^{h}}{\lambda+1}\right)$

$E\left(V^{h}\right)=\lambda \ln \left(\frac{2 I^{0}-c}{\lambda+1}\right)+p \lambda \ln \left(\frac{I^{m}+\underline{I}^{h}}{\lambda+1}\right)+(1-p) \lambda \ln \left(\frac{I^{m}+\bar{I}^{h}}{\lambda+1}\right)$ 


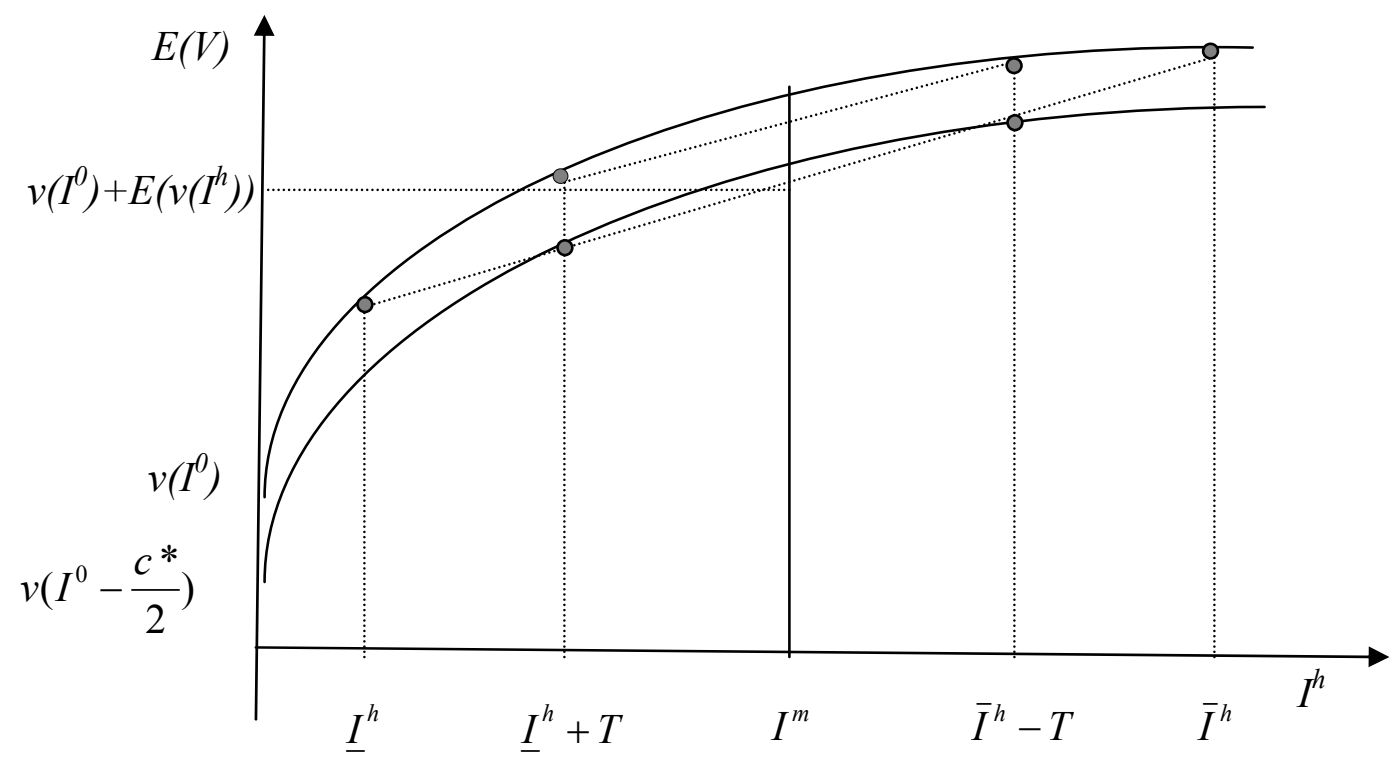

The insurance and the altruistic motives share similar predictions with respect to the sign of the effects of pre-transfer income levels on the amounts remitted. However, they differ with respect to the predicted timing of remittances and, to a lower extent, the predicted effect of familial wealth on the size of remittances. As to the timing of remittances, the insurance model predicts that migration and attached remittances are more likely where income at origin is more volatile, and that remittances should be sent on a relatively irregular basis. Moreover, if one admits that altruism is solvable in distance and time, the altruistic model should imply a gradual decrease of remittances over time, while the insurance motive should imply no decrease during a given period (if specified contractually), and a sharp decline after a while. Another difference between the two hypotheses is that while purely altruistic models predict higher remittances to lower-income households, ceteris paribus, the bargaining model of insurance could imply the opposite for two reasons: first, recall that migration is more worthy - and, hence, more likely - for families holding sizeable 
(and relatively risky) assets; in addition, we know from the bargaining-cum-exchange model that greater familial wealth increases the family's bargaining power. Therefore, with an insurance rationale, the prediction according to which the likelihood and size of remittances should decrease with recipients' incomes may be true for a given household (as in the case of altruism) but not necessarily so across households (in contrast to altruism).

In addition, the number of migrants within a given household may also provide a basis for discrimination between altruism and insurance. As pointed out by Agarwal and Horowitz (2002), the number of migrants is expected to reduce altruistic transfers by any particular migrant as all sources of transfers (whether public or private) are perfect substitutes under the pure altruistic hypothesis. By contrast, if each migrant individually subscribes an insurance contract, no such negative effect is expected. This argument is essentially correct but neglects two aspects that must be kept in mind regarding the exogeneity of the number of migrants, on the one hand, and of the recipients' income, on the other hand. The exogeneity of the number of migrants may be questioned as households living in more volatile environments (or with higher degrees of risk aversion) have an incentive to send more migrants out and further diversify their portfolio of income sources; at the same time, liquidity constraints may prevent poor households from attaining optimal diversification, an issue we explore in more details below. The exogeneity of the recipients' income may also be questioned since, as agents become insured against risks, they may reduce their level of effort (moral hazard).

To illustrate this problem, we present a simple model adapted from Azam and Gubert (2002). Assume that there is no altruism, and the household's pre-transfer income depends on its productive effort and on the realization of an idiosyncratic risk 
that impede on local production. Assuming an increasing marginal disutility of effort, and using an additive-separable form, the household's utility function may be written as:

$$
V^{h}\left(E\left(C^{h}\right), e\right)=E\left(C^{h}\right)-\frac{\omega}{2} e^{2}
$$

where the parameter $\omega$ is positive and $e$ denotes the household's level of effort.

Assume that there are only two states of nature, and that it is only in the "good" state of nature, which occurs with probability $p$, that local production is conditioned upon the household's productive effort. In the "bad" state of nature, on the other hand, local production is brought to a minimum regardless of the household's effort. Without loss of generality, we normalize this minimal level to zero so that we have:

$$
I^{h}=\left\{\begin{array}{l}
\alpha e \text { with probability } 0<p<1 \\
0 \text { with probability }(1-p)
\end{array}\right.
$$

where $\alpha$ is the marginal productivity of the household's effort.

Assume moreover that the insurance contract specifies that the migrant guarantees a minimal consumption level to the household, $I^{\mathrm{min}}$. Remittances are then given by:

$$
T=\operatorname{Max}\left\{I^{\min }-I^{h}, 0\right\}
$$

The household's expected utility is, therefore:

$$
E\left(V^{h}\right)=p\left[\alpha e+\operatorname{Max}\left\{I^{\min }-\alpha e ; 0\right\}\right]+(1-p) I^{\min }-\frac{\omega}{2} e^{2}
$$

which gives the first-order conditions and the corresponding levels of effort:

$$
\frac{\partial E\left(V^{h}\right)}{\partial e}=\left\{\begin{array}{l}
p \alpha-\omega e \leq 0 \text { if } \alpha e \geq I^{\min } \Rightarrow e_{1}^{*}=\frac{p \alpha}{\omega} \\
-\omega e \leq 0 \text { if } \alpha e<I^{\min } \Rightarrow e_{2}^{*}=0
\end{array}\right.
$$

The household chooses its effort level so as to maximize its expected utility; the optimal solution is derived from a comparison between:

$$
E\left[V^{h}\left(e_{1}^{*}\right)\right]=\frac{1}{2} \frac{p^{2} \alpha^{2}}{\omega}+(1-p) I^{\min }
$$

and

$$
E\left[V^{h}(0)\right]=I^{\min }
$$


The condition required to obtain a positive level of effort is, therefore:

$$
E\left[V^{h}\left(e_{1}^{*}\right)\right]>E\left[V^{h}(0)\right] \Leftrightarrow \frac{1}{2} \frac{p^{2} \alpha^{2}}{\omega}+(1-p) I^{\min }>I^{\min } \Leftrightarrow \frac{1}{2} \frac{p \alpha^{2}}{\omega}>I^{\min }
$$

which will be referred to as the "no moral hazard condition". If condition (2.29) holds, then, we have:

$$
\begin{aligned}
& E\left(C^{h}\right)=\frac{p^{2} \alpha^{2}}{\omega}+(1-p) I^{\min } \\
& E(T)=(1-p) I^{\min } \\
& E\left(C^{m}\right)=I^{m}-(1-p) I^{\min }
\end{aligned}
$$

It should be noted that the migrant has the possibility to fix the minimal consumption level to avoid opportunistic behavior. For example, choosing $I^{\min }=\frac{1}{2} \frac{p \alpha^{2}}{\omega}$ rules out the possibility of a moral hazard equilibrium. In this particular case, the expected amount of transfer becomes $E(T)=\frac{(1-p) p \alpha^{2}}{2 \omega}:$ it is a quadratic function of $\alpha$, the marginal productivity of effort (which may also be seen as an indicator of the household's level of productive assets).

There are, however, theoretical as well as empirical justifications to focus on cases where condition (2.29) does not hold. At an empirical level, some studies provide evidence of opportunistic behavior on the recipients' side (e.g., Azam and Gubert (2002) in the case of rural Mali - see section 2.2 below). At a theoretical level, it may seem too optimistic to assume that all the parameters in (2.29) are known to the migrant. Alternatively, one may view the minimal level of consumption as resulting from a collective decision taken before migration. It could also be argued that any amount satisfying (2.29) falls below the optimal altruistic transfer decided by the migrant himself. In all of these cases, the condition (2.29) does not hold and a moral hazard equilibrium emerges; it is defined by:

$$
\begin{aligned}
& E\left(C^{h}\right)=I^{\min } \\
& E(T)=I^{\min } \\
& E\left(C^{m}\right)=I^{m}-I^{\min }
\end{aligned}
$$

Note that without insurance (remittances), the level of effort would be chosen so as to maximize:

$$
E\left(\widetilde{V}^{h}\right)=p \alpha e-\frac{\omega}{2} e^{2}
$$


which would yield:

$$
\widetilde{e}^{*}=e_{1}^{*}=\frac{p \alpha}{\omega}
$$

and

$$
E\left(\widetilde{V}^{h}\right)=\frac{p^{2} \alpha^{2}}{2 \omega}
$$

One can see that under the "no moral hazard condition" (2.29), the insurance contract does not distort individual effort (this is of course by definition, and is apparent from the comparison between (2.26) and (2.31)) but generates an increase in the recipient's expected utility, which may be interpreted as the value of the insurance contract from the recipient's standpoint:

$$
E\left[V^{h}\left(e_{1}^{*}\right)\right]-E\left[\widetilde{V}^{h}\right]=(1-p) I^{\min }
$$

In the case where condition (2.29) is not satisfied, the insurance contract induces a moral hazard equilibrium characterized by a minimal level of effort; in this case, the expected value of the insurance contract becomes:

$$
E\left[V^{h}(0)\right]-E\left[\widetilde{V}^{h}\right]=I^{\min }-\frac{p^{2} \alpha^{2}}{2 \omega}
$$

An interesting implication of this analysis is that if the household is ready to finance a migration cost higher than (2.33), this signals its intention to adopt an opportunistic behavior and reduce its effort. Figure 2.2. represents the case where the "no moral hazard condition" (2.29) holds. The dotted line depicts the ex-ante budget constraint (i.e., before the state of nature is realized) without insurance contract. The solid line represents the ex-ante budget constraint with insurance (recall that the expected income cannot be lower than $I^{\mathrm{min}}$ ). The "no moral hazard conditions" requires that the expected utility level with a positive effort must be higher than without effort (i.e., $V_{1}^{h}>V_{2}^{h}$ ): in this case, the equilibrium is at point $N$. Otherwise (i.e., if $V_{1}^{h}<V_{2}^{h}$ ), the insurance contract has a distorting effect on effort, and the equilibrium is at point $D$. 


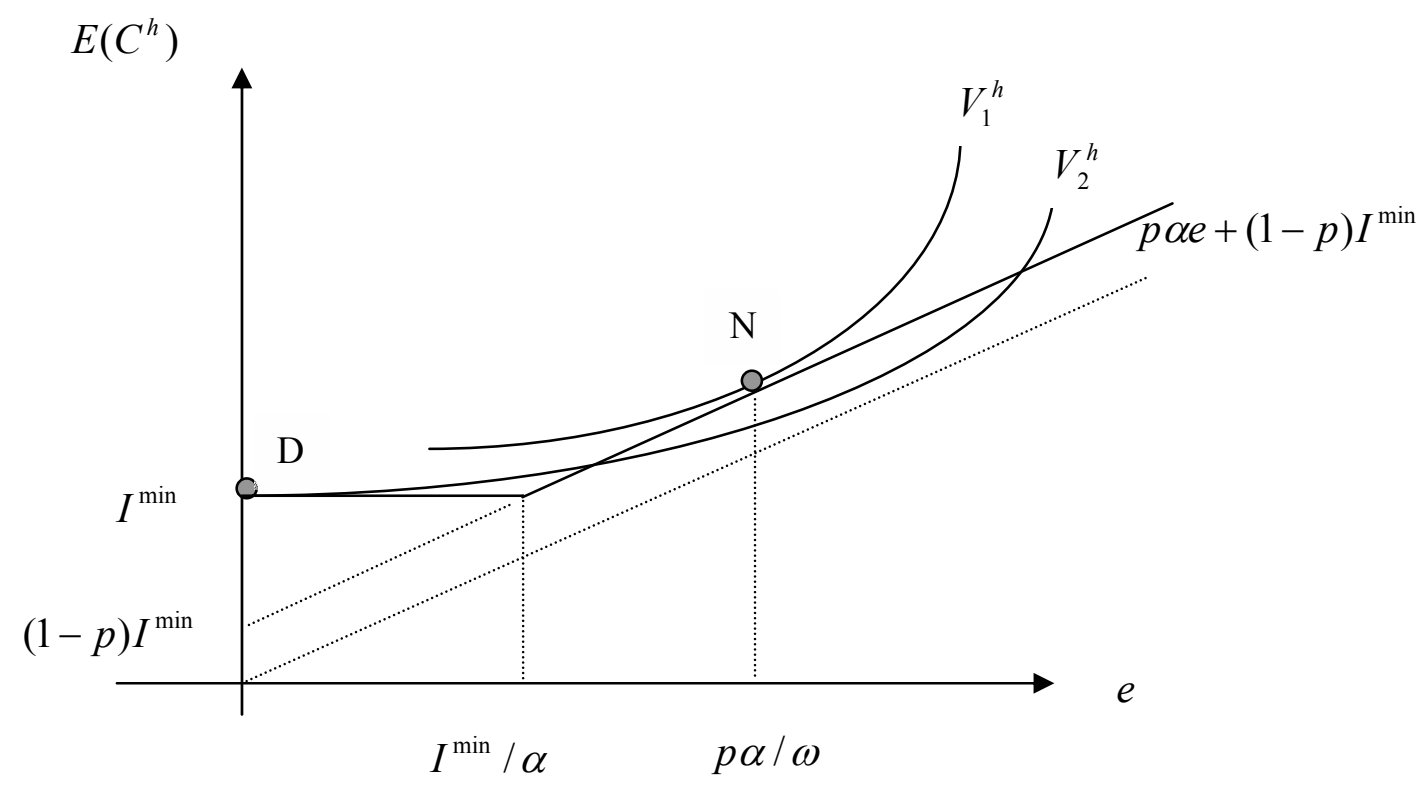

\subsubsection{Family loan arrangements: the investment motive}

The same kind of rationale may be used to explain remittances as repayments of loans on investments in education and/or migration. In this case, the familial implicit contract aims at increasing family income rather than at reducing uncertainty. Implementing such loans may require complex decision procedures as to the amount to be financed, the various sources to be solicited for fund-raising, and the recipients of the loans. The investment motive may be seen as a particular exchange of services in a context of imperfect credit markets, following the general lines we presented in our exposition of the exchange motive, but within a framework containing social as well as intergenerational elements.

The idea that remittances consist at least partly of repayments of loans has long been present in the remittance literature, especially in the empirical studies on the determinants of remittances. However, to the best of our knowledge, it is only recently that it has explicitly been modeled theoretically. ${ }^{15}$ A relatively neglected aspect of the debate on remittances as dividends from investments concerns the interplay between migration, remittances, and the distribution of wealth among rural

\footnotetext{
${ }^{15}$ For example, Lucas and Stark (1985) refer to the investment hypothesis, but, as they put it, just offer outlines for the underlying theory. Cox and Jimenez (1992) seem to be the first to provide a theoretical framework for the investment hypothesis, followed by Cox, Eser and Jimenez (1998) and Ilahi and Jafarey (1999). One should also mention Poirine (1997), who derives many interesting implications from his simple diagrammatic model.
} 
households. Indeed, if investments are the underlying familial motivation for sending migrants away, this implies that the family will keep on sending migrants as long as family income is thereby increased. Since migration is costly, however, this also implies that liquidity constraints impede on the number of migrants that can be sent by a given family, and that richer families are more likely to take advantage of such investment opportunities. In the following, therefore, we discuss the implications of the investment hypothesis on the size and likelihood of remittances in connection with inter-household economic inequality. We neglect enforcement problems, since these are identical to those detailed above for the insurance motive. Besides, we focus on the level of familial assets, although it is clear that the composition of such assets could also be of importance.

Consider a family of unitary size, making its living from agriculture. Total familial output in agriculture is represented by a quadratic production function, $\alpha\left(\ell-\frac{\beta}{2} \ell^{2}\right)$, where $\ell$ is the number (or proportion) of workers employed in the domestic activity (typically, one minus the number of migrants), $\alpha$ is a technological parameter capturing the quantity and quality of familial land, and $\beta$ accounts for the decreasing marginal productivity of labor.

Since we are interested in inter-household inequality and not in the intrafamilial distribution of income, for the sake of simplicity, we assume that income is equally shared between the members of a given family. Agents live for two periods. Without migration, income per member at each period is given by:

$$
I_{1}^{h}=I_{2}^{h}=\alpha-\frac{\alpha \beta}{2}
$$

Assume that there is a migration possibility to a high-wage destination at a fixed cost $c$ per migrant. In the absence of credit markets, this cost - which may include education expenditures - must be financed using first-period savings. Migration occurs in the second period, so that $\ell=1$ in the first period. We denote by $m$ the number (or proportion) of family members who migrate in the second period, and the migrants' wages by $I^{m}$. The labor force employed in the domestic activity is thus $\ell=1-m$. Utility is linear in income since we assume no risk-aversion and there is no inter-temporal discounting of income. Moreover, we assume that there is a 
minimal level of subsistence, $I^{\text {min }}$, which must be kept for consumption at each period, but this minimum level could be set at zero without loss of generality.

The effect of familial wealth (captured by the technological parameter $\alpha$ ) on the number of migrants is a priori unclear. On the one hand, migration incentives would seem to be greater for members of poor families, since their foregone earnings are lower than those of members of rich families (or, in other words, the wage differential is higher for poor families). On the other hand, poor families are likely to be liquidity constrained and hence unable to finance every profitable migration. That is, for each family, there may be a difference between the maximal number of migrants that the family can afford and the number of migrants that is optimal from its perspective.

To find how binding the liquidity constraint is, let us first determine the maximal number of migrants for a given family. The constraint may be written in the following form:

$$
\alpha\left(1-\frac{\beta}{2}\right)-m c \geq I^{\min } \Leftrightarrow m \leq \frac{\alpha}{c}\left(1-\frac{\beta}{2}\right)-\frac{I^{\min }}{c} \equiv m^{c}(c, \alpha)
$$

Clearly, this maximal proportion of migrants increases with the technological parameter $\alpha$ but decreases with the migration cost and the minimum of subsistence.

As to the optimal (unconstrained) proportion of migrants, it is derived from the maximization of total family income:

$$
\underset{m}{\operatorname{Max}} \alpha-\frac{\alpha \beta}{2}-m c+\alpha(1-m)-\frac{\alpha \beta}{2}(1-m)^{2}+m I^{m}
$$

This gives:

$$
m^{*}=\left\{\begin{array}{c}
0 \text { if }-\alpha+\alpha \beta+I^{m}-c<0 \\
1 \text { if }-\alpha+I^{m}-c>0 \\
\frac{I^{m}-c}{\alpha \beta}-\frac{1-\beta}{\beta} \text { otherwise }
\end{array}\right.
$$

The actual proportion of migrants is the minimum between the optimal and the constrained proportions: $m^{e f f}=\operatorname{Min}\left\{m^{*} ; m^{c}\right\}$. Clearly, for interior solutions, the constrained migration rate increases with $\alpha$ while the optimal rate decreases with $\alpha$. Note also that $m^{*}$ is a linearly decreasing function of $c$ and $m^{c}$ is a decreasing and convex function of $c$. 
In keeping with the equal sharing rule assumed above, the amount received by each remaining resident is given by the difference between the average familial income, $I^{m} m^{e f f}+\alpha\left(1-m^{e f f}\right)-\frac{\alpha \beta}{2}\left(1-m^{e f f}\right)^{2}$, and the domestic income per remaining member, $\alpha-\frac{\alpha \beta}{2}\left(1-m^{e f f}\right)$. This gives:

$$
T=m^{e f f}\left[I^{m}-\alpha+\frac{\alpha \beta}{2}\left(1-m^{e f f}\right)\right]
$$

which is a concave function of the migration rate.

The total derivative of remittances with respect to the technological parameter $\alpha, \frac{d T}{d \alpha}=\frac{\partial T}{\partial m^{e f f}} \frac{d m^{e f f}}{d \alpha}+\frac{\partial T}{\partial \alpha}$, may be positive or negative depending on the volume of migration as well as on the regime observed (constrained or unconstrained migration).

Hence, given (2.36), (2.38) and (2.39), this familial model of investment in migration provides interesting predictions on the relationship between the amount of remittances received by each remaining household member and the level of his/her pre-transfer income. More precisely, for interior solutions, the model predicts an inverse U-shaped relationship between remittances and family income. To illustrate this, we present numerical simulations, with the following values of the parameters: $\beta=.8, I^{\min }=0, I^{m}=30, c=10$ and $10<\alpha<30$. The results are apparent from Figure 2.3.: for $\alpha<18.7$, migration is constrained and the relationship between the amount of remittances received and the recipient's pre-transfer income is concave; for higher values of $\alpha$, migration is unconstrained and the relationship between remittances and income is always decreasing. These results are robust to the choice of the values of the parameters (provided that an interior solution for $m *$ holds). 
Figure 2.3: Volume of remittances per remaining household member (Y-Axis) and average pre-transfer income (X-Axis), with $10<\alpha<30$.

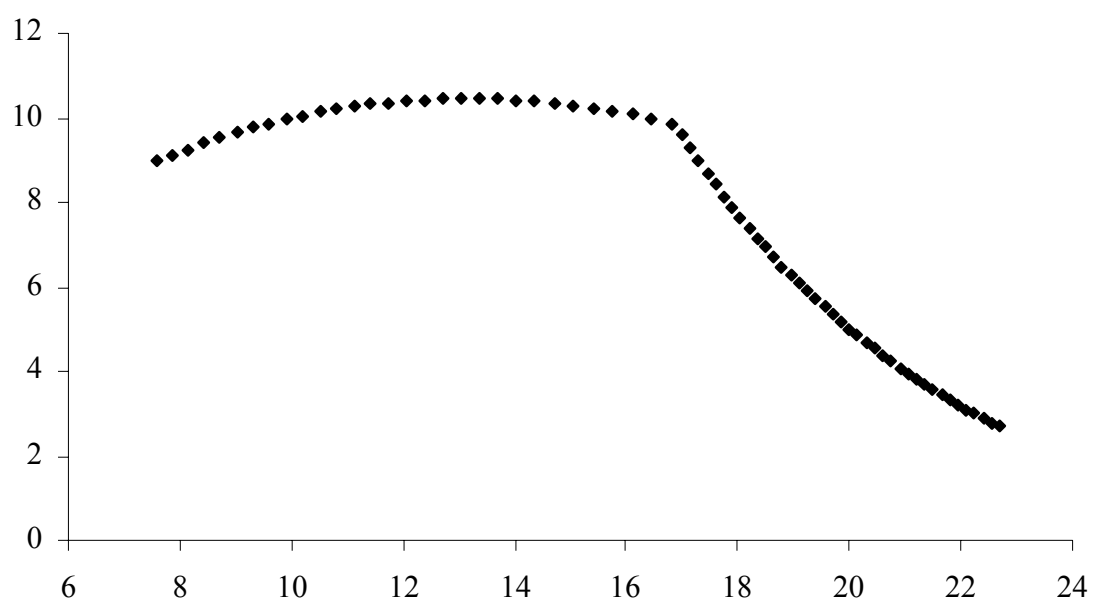

Such an inverted U-shaped relationship between remittances received and average pre-transfer income, which is the main prediction of our investment model, is confirmed by a number of empirical studies on migration and inequality (see the macroeconomic section below).

As emphasized above, the migration cost to be financed by the family may include physical and informational migration costs as well as education expenditures. With this latter case in mind, Poirine (1997) concluded that if the "loan" element is more important than the "altruistic" and the "insurance" elements, three consequences should follow: first, remittances should not be used for capital investment by the receiving family; second, they should be a regular payment, with no tendency to decay over time; and third, their amount should depend on the magnitude of the loan received.

In addition, as pointed out by Lucas and Stark (1985), the fact that more educated migrants tend to remit more is not a discriminative test of whether remittances are a repayment of the principal (plus interest) invested by the family in the migrant's education. Indeed, since more educated persons tend to earn more, the altruistic model would predict the same result. Lucas and Stark (1985) thus suggested that since a given receiving household is likely to have borne education expenditures for its own children only (its "own-young") but not for, e.g., sons or daughters in law, the investment hypothesis implies that repayments by the former group should be higher at given education levels. However, combining the common sense that altruism 
towards one's immediate family is stronger than towards one's family-in-law with the now well-known result that income shares matter for intrahousehold resource allocation (e.g., Thomas, 1990, Duflo and Udry, 2003) makes the prediction on the "own-young" less decisive than expected.

Finally, the "investment" motive may be distinguished from the broader exchange motive as to the effects of unemployment on remittances. In our presentation of the exchange motive, we indicated that unemployment at home, in lowering the bargaining power of the recipient, tends to decrease the amount transferred. On the contrary, since education provides at least partly an insurance against unemployment, higher unemployment at home increases the value of education and, therefore, should positively affect the contractual terms for the family and translate into higher remittances (Stark and Bloom, 1985).

\subsubsection{Inheritance as an enforcement device}

It may reasonably be argued that remittances would take place when there is a welfare gain for all the parties concerned. Except perhaps in the case of perfect mutual altruism ( $\beta=1 / 2$ for each agent) in which all agents agree on the level of transfer, a specific arrangement between senders and recipients may be required when other or weaker motives apply. Indeed, the temporal structure of the interaction is conducive to opportunistic behavior. A first important problem with family agreements is to ensure that the sender will remit the amount implicitly agreed upon in the informal contract. When the degree of altruism is not sufficient to secure remittances, the migrant may be inclined to renege on his contractual obligations. When remittances and compensations occur simultaneously, the incentive to respect the contract is stronger since the sanction is immediate. But when remittances and compensations occur at different periods of time, there is a strong incentive to deviate from the contractual terms. For example, if remaining households first cover the migrants' migration costs and then expect to receive compensating transfers in the future, how may such an arrangement be enforced?

Two basic mechanisms generally serve as enforcement devices to make family arrangements incentive compatible: punishment, and social norms (however, social norms themselves may be viewed as a trigger of social sanctions, i.e. punishments imposed by society at large). At a family level, the most obvious threat that may be 
used to secure remittances is the possibility of depriving the migrants of their rights to inheritance and/or return. From an economic perspective, this refers to the theory of strategic bequest initiated by Bernheim, Shleifer and Summers (1985). The central premise of this theory is that parents use bequests to monitor the behavior of their children, allocating bequests among siblings according to their relative attention. Using U.S. data, Bernheim, Shleifer and Summers found supportive evidence of their theory. Hoddinott (1994), Subramanian (1994), and de la Brière et al. (2002) applied a similar approach to the case of developing countries. Instead of developing a formal model, we just provide a sketch of the main assumptions and summarize the predictions of these studies.

Following Hoddinott (1994), assume that there is a benchmark, minimal amount of money that each migrant is expected to remit. Hoddinott argues that parents can encourage transfers above this benchmark level by offering a "reward" in the form of land or any other inheritable asset. According to that view, remittances may be seen as a pure strategy of investment in inheritance on the side of the migrant and as an enforcement device to secure remittances on the side of the family. A natural extension of this model would be to allow for multiple migrants competing for inheritance within a given family; from the rent-seeking contests literature, ${ }^{16}$ we would expect remittances per migrant to first increase and then decrease with the number of other migrants as the effect of competition is offset by the decrease in one's probability of inheritance. Recently, de la Brière et al. (2002) summarized the main predictions of this inheritance motive (which they called the investment hypothesis) as follows: the amount of remittances increases with (a) the remaining household's assets and income, (b) the probability of inheriting (which depends on the age of the parents, the number of siblings, etc.), (c) the migrant's wealth and income, and decreases with (d) the degree of risk aversion, providing that inheritance is more risky than other available forms of savings.

\subsubsection{Mixed motives}

Obviously, one should not expect remittances to be driven by a single motive. In reality, a combination of different motives applies, with the exact mixture varying

\footnotetext{
${ }^{16}$ See Nitzan (1994) for a theoretical survey.
} 
over times and places. In our presentation of the different motives above, we insisted that discriminative tests are not always available. Were they, it would still be quite presumptuous to infer from their results that a particular motive is dominant in explaining remittance behavior. It is not only that different individuals may be heterogeneous in their motivations to remit, but also that different motivations to remit may coexist within the same individual. For example, informal family contracts may contain a loan as well as an insurance element, the enforcement of which depending on loyalty and trustworthiness, these concepts being somehow related to altruism. Such complex interdependencies have long been recognized in the empirical literature (e.g., Lucas and Stark, 1985) and, more recently, in the theoretical literature. For example, Cox, Eser and Jimenez (1998) or Feinerman and Seiler (2002) combine altruism and exchange, ${ }^{17}$ Foster and Rosenzweig (2001) combine altruism and mutual insurance, and Docquier and Rapoport (2000) combine altruism and the strategic motive. These approaches have in common that altruism may hide the existence of other underlying motives, thus making them either irrelevant or undetectable. For example, altruistic transfers tend to smooth interpersonal consumption levels, thus rendering the need for insurance less urgent; besides, altruistic transfers may also induce counter-gifts in the form of services provided under the rule of reciprocity.

To illustrate this complexity - and the difficulty inherent to the design of appropriate empirical tests -, we give a simple diagrammatic exposition of a situation where altruistic transfers induce a particular "service" in return. More precisely, we show that altruistic remittances bring about a specific by-product consisting in the achievement of positive selection among migrants. We choose this example for its heuristic properties, but the same argument could apply to other types of services. Assume that the conditions required for strategic transfers to be observed apply, and, for simplicity, that the migrant only is altruistic toward the non-migrant. Using our previous notations and a logarithmic utility function (see the previous section on altruism), this means that we have $\beta^{m}=\gamma^{m}>0, \beta^{h}=\gamma^{h}=0$, and the migrant's

\footnotetext{
${ }^{17}$ Feinerman and Seiler (2002) extend the framework developed by Cox and his co-workers to describe the interaction between an altruistic donor (a parent seeking attention from children) and multiple selfish beneficiaries of different types (children for which time devoted to visit parents is more or less costly), with imperfect information on the latter's types. In this context they explore how parental altruism affects selection into the pool of beneficiaries as well as the amounts transferred and the volume of services received. They notably contrast their results to the case of symmetric information and show that under imperfect information, increases in parental altruism towards one given child
} 
utility is maximal when $\frac{C^{h}}{C^{m}}=\frac{\gamma^{m}}{1-\gamma^{m}}$. In this setting, it is clear that the altruistic remittance from $m$ to $h$ may be high enough to prevent unskilled workers' migration without having to rely on strategic side-payments. This is the case when the "spontaneous" altruistic transfer is higher than the amount required for positive selection to be obtained. This is illustrated on Figure 2.4.:

Figure 2.4: When altruism makes a particular exchange motive irrelevant

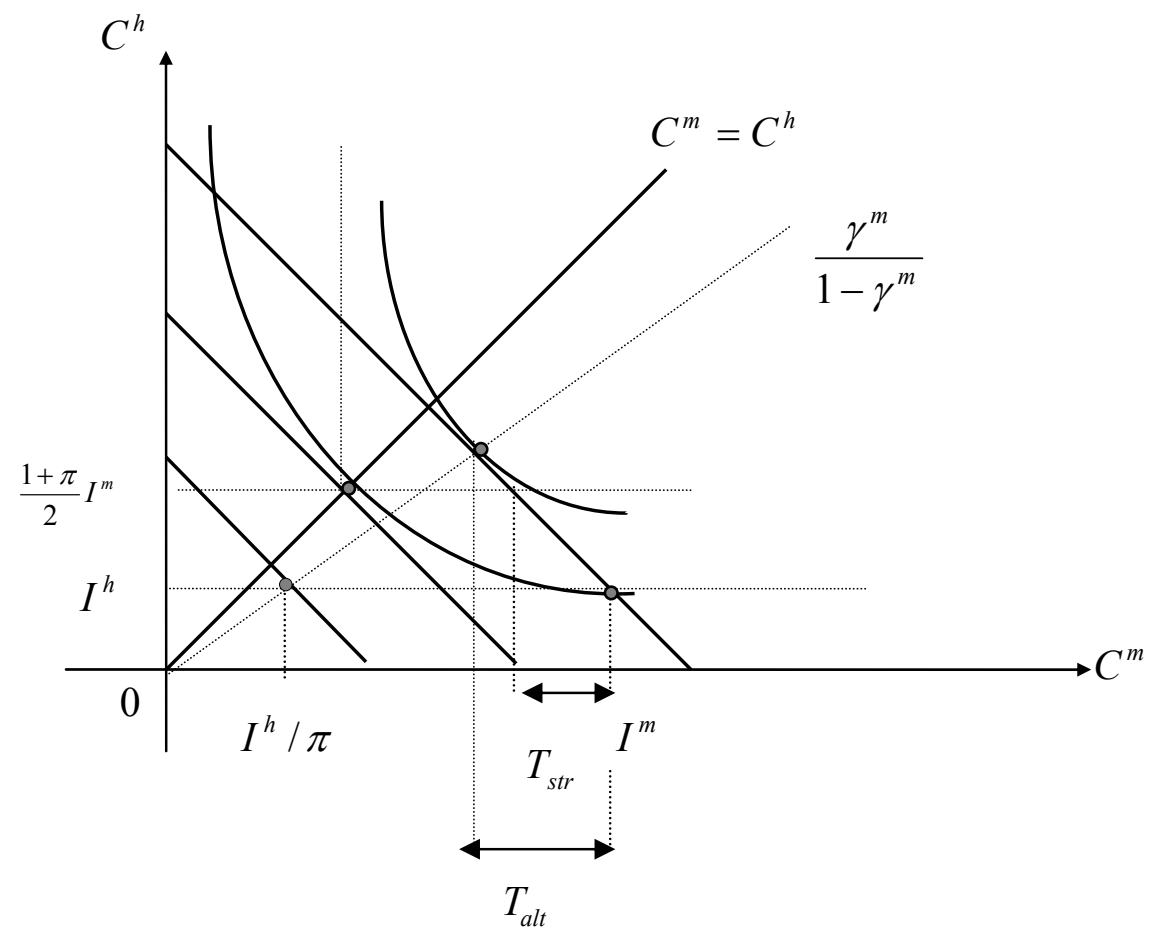

As apparent from Figure 2.4., if both $m$ and $h$ migrate, total income is $(1+\pi) I^{m}$ and each agent receives $\frac{1+\pi}{2} I^{m}$. If $m$ alone migrates, total income is increased to $I^{m}+I^{h}$. The minimal strategic transfer (or side-payment) required to prevent $h$ 's migration, $T_{\text {str }}$, is lower than the altruistic remittance that $m$ would choose if migrating alone, $T_{a l t}$. Anticipating this, $h$ would rationally choose not to migrate.

raises the volume of trade (attention time versus transfers) with that child at the expenses of the other, ceteris paribus. 


\subsubsection{Summary of predictions}

Before we discuss the empirical evidence on migrants' remittances, let us first summarize the predictions derived from the different models just exposed. In an attempt to clarify whether a given prediction is distinctive of a particular theory, Table 2 presents the six motives for remittances in the columns, including the four individualistic motives (altruism, exchange, inheritance, and the strategic motive) and two types of familial agreements (on insurance and investment) reviewed so far. For each theory, the table indicates the sign of the marginal effect of nine explanatory variables on the amount of remittances. We restrict the analysis to explanatory variables: (i) for which panel data can reasonably be collected, and (ii) that potentially allow for discriminating between competing theories. The mention "no direct effect" (nde) means that the parameters associated to the corresponding variable are expected to be non-significant, at least if the other relevant controls are introduced. For example, once the migrants' incomes are taken into account, their education level should not play any role under the altruistic hypothesis but is expected to impact negatively on remittances under the exchange hypothesis (as educated migrants have lower propensities to return) and to have a positive impact on remittances under the investment hypothesis. Note also that the last line of the table (as well as the cells marked with $\mathrm{a}^{*}$ ) signals the predictions that are specific to a particular approach and as such provide a basis for the conception of discriminative tests.

As can be seen from the table, pure altruism can be singled out as a motivation to remit thanks to the specific prediction on the transfer-income derivative. In addition, and assuming that altruism decreases with time and familial distance, the size of remittances should be negatively related to these two variables in the altruistic case. The possibility of a positive impact of recipients' income on transfers is a specific prediction of the exchange motive (although a negative relationship is also compatible with exchange, as we have seen); to a lower extent, a negative effect of education levels could also be seen as supportive evidence of exchange motivations. Under the inheritance hypothesis, the amounts remitted should in principle be independent of the recipients' incomes (once their wealth is introduced) but are expected to be closely related to the probability of receiving inheritance; in turn, this probability depends on the quantity of assets held by the remaining household members as well as on the number of heirs (the sign of the latter variable, however, would seem to be ambiguous: on the one hand, sharing the parental assets with the 
other heirs should reduce the incentives to remit, but competition among heirs could well stimulate remittances). ${ }^{18}$

The strategic motive may easily be contrasted to altruism as it predicts: (i) a transfer response to changes in pre-transfer incomes higher than one, and (ii) a one-toone substitution effect of recipients' income; moreover, strategic transfers are likely to come to an end once individuals' productivity is revealed. The insurance mechanism, on the other hand, implies that transfers should not depend on migrants' and recipients' long-run incomes; it may further be contrasted to the inheritance motive in that in the case of insurance, short-run income shocks on the recipient's side are key determinants of remittances, which should be observed on an irregular basis and be correlated with aggregate productivity indicators such as drought indices. Finally, under the investment motive, remittances have a loan repayment component and should therefore be related to the amounts invested by the family in the migrant's education and/or moving costs: remittances are therefore expected to increase with the migrant's education and with geographic distance; in addition, from an exchangebargaining perspective, the investment motive (and, to some extent, the insurance motive) may give rise to an inverse U-shaped relationship between transfers and recipients' incomes.

Discriminating between these different motives requires collecting panel data on a large number of variables. Such a time-series dimension is required to distinguish between the effects of "permanent" changes in income (typically proxied by a moving average of past and present income levels) and those of short-run income shocks. Moreover, a time-series dimension is obviously necessary to capture the exact timing of transfers; this is critical, in particular, to discriminate between insurance and inheritance, as explained above. The number of variables is also important in its own right. For example, the migrants' education (even if correlated with income) is required to discriminate between the investment motive and all the other motives. Controlling for the recipients' wealth (even if this is clearly correlated with income) is necessary as well, notably to test for the presence of an inheritance motive. As the above discussion makes clear, working with a limited data set makes it impossible to reach any decisive conclusion regarding the underlying motives for remittances.

\footnotetext{
${ }^{18}$ Intuitively, one may expect a non-linear relationship, with the competition effect dominating when the number of heirs is small and the sharing effect becoming dominant when the number of heirs is relatively large.
} 
Table 2: Remittances' sensitivity to various explanatory variables - a summary

\begin{tabular}{|c|c|c|c|c|c|c|}
\hline Motives & \multicolumn{4}{|c|}{ Individual motives } & \multicolumn{2}{|c|}{ Familial arrangements } \\
\hline Expl. Variables & Altruism & Exchange & Inheritance & $\begin{array}{c}\text { Strategic } \\
\text { motive }\end{array}$ & Insurance & Investment \\
\hline Migrant's income & $>0$ & $>0$ & $>0$ & $>0$ & nde $(*)$ & $>0$ \\
\hline Migrant's education & nde & $<0(*)$ & nde & $>0$ & nde & $>0(*)$ \\
\hline Time since arrival & $\leq 0$ & nde & nde & $\leq 0$ & nde & nde \\
\hline Distance from family & $\leq 0$ & nde & $<0$ & nde & nde & $>0$ \\
\hline $\begin{array}{l}\text { Number of } \\
\text { migrants/heirs }\end{array}$ & $<0$ & nde & $\begin{array}{l}\text { Inverse U- } \\
\text { shape effect }\end{array}$ & nde & nde & nde \\
\hline $\begin{array}{l}\text { Recipient's long run } \\
\text { income }\end{array}$ & $<0$ & $>_{0}^{>}(*)$ & $\operatorname{nde}(*)$ & $<0$ & $\operatorname{nde}(*)$ & $\begin{array}{l}>0 \\
<\end{array}$ \\
\hline $\begin{array}{l}\text { Adverse short run shocks } \\
\text { in recipients' income }\end{array}$ & $>0$ & ${ }_{<}^{>}{ }_{0}(*)$ & nde & $>0$ & $>0$ & $>0$ \\
\hline $\begin{array}{l}\text { Recipient's assets (land, } \\
\text { cattle, etc.) }\end{array}$ & nde & nde & $>0(*)$ & Nde & Nde & nde \\
\hline Specific predictions & $\frac{\partial T}{\partial I^{m}}-\frac{\partial T}{\partial I^{h}}=1$ & $\begin{array}{l}\text { It is possible } \\
\text { that } \frac{\partial T}{\partial I^{h}}>0\end{array}$ & $\begin{array}{c}\text { Role of } \\
\text { parental } \\
\text { assets and } \\
\text { number of } \\
\text { heirs }\end{array}$ & $\begin{array}{c}\text { (i) } \\
\frac{\partial T}{\partial I^{m}}-\frac{\partial T}{\partial I^{h}}>1 \\
\text { (ii) } \\
\frac{\partial T}{\partial I^{h}}=-1\end{array}$ & $\begin{array}{l}\text { (i) Irregular } \\
\text { basis } \\
\text { (ii) No } \\
\text { effect of } I^{h} \\
\text { in the long } \\
\text { run }\end{array}$ & $\begin{array}{l}\text { Inverse U- } \\
\text { shaped } \\
\text { effect of } I^{h}\end{array}$ \\
\hline
\end{tabular}

Note: $n d e=$ no direct effect (after controlling for migrants' and/or recipients' incomes)

(*) Remarkable prediction 


\subsection{Evidence}

The theoretical models presented above have highlighted the role of a number of critical variables in explaining remittance behavior: levels of current and expected pre-transfer income of migrants and recipients, income volatility at home and destination, or current and expected levels of unemployment at home and destination. Individual characteristics obviously play a role that cannot be overstressed: first of all whether the migrant's immediate family is living back in the country of origin, and also the migrant's education and gender, ${ }^{19}$ the number of heirs and migrant members within a given household, the assets hold by the remaining household, etc. Other variables (e.g., marital status, gender of the household's head, etc.) may also play a role and will be mentioned in the course of the presentation of the empirical studies.

The main issue addressed in most empirical studies concerns the degree of altruism that may be inferred from the migrants' behavior. Before we detail the results from selected studies on remittances, it may be worth keeping in mind that similar studies on the determinants of private transfers in developed countries have generally rejected the pure altruism hypothesis. The reference on this is probably Altonji, Hayashi and Kotlikoff (1997); using American data on interpersonal private transfers (and controlling for uncertainty and liquidity constraints, functional forms, number of siblings, etc.), they rejected the altruistic hypothesis (at least for transfers between parents and their children). Indeed, they estimated a transfer-income derivative in the $.04-.13$ range, far from the unitary value predicted by the pure altruism model. This result confirmed their previous findings (Altonji, Hayashi and Kotlikoff, 1992), which showed that the distribution of consumption within the family was dependent on the distribution of income. As we shall see, most studies on the determinants of migrants' remittances in developing countries also conclude that pure altruism is unlikely to be a good working assumption.

The first empirical study to accurately discriminate between various motivations to remit is the important work of Lucas and Stark (1985) on Botswana. In this pioneering study, Lucas and Stark found that remittances rise steadily with the migrants' earnings, which is consistent with a variety of motives, as explained above,

\footnotetext{
${ }^{19}$ Recall that we indicated that daughters are often thought to be more trustworthy and caring than sons. This seems to be a rational belief since a number of studies (e.g., Lucas and Stark, 1985, for Botswana, and Kaufmann and Lindauer, 1986, for El Salvador) show a positive relationship between remittances and female status.
} 
including altruism. However, pure altruism would imply that remittances are primarily directed to low-income households, while Lucas and Stark's estimates show a positive relationship between the level of remittances received and households' pretransfer income. This suggests that exchange, investment and inheritance could play a key role in determining remittance flows.

To discriminate between these different possibilities, Lucas and Stark (1985) first established that remittances rise significantly with the migrant's years of schooling, but more so among the recipient household's "own young" (children, grandchildren, nephews and nieces, as opposed, e.g., to sons and daughters in law), showing that remittances are likely to result from an understanding to repay initial educational investments. When interacted with a dummy for "own young", however, the coefficient on years of schooling turned out to be positive but not highly significant. In addition, as we mentioned earlier, intrahousehold bargaining models could also potentially account for this result. Another direction was then explored to control for inheritable assets. Botswana's inheritance customs and laws are quite diverse, but sons are roughly more likely to inherit than daughters or other household members. Since most agricultural lands are common property, cattle are the dominant form of inheritable wealth. The authors thus added a dummy variable for whether the household holds a cattle herd larger than 20 beasts. The results showed that indeed, sons remit more to families with larger herds while the associated coefficient is weakly negative for daughters and their spouses. Hence, sons behave significantly differently from daughters and other relatives in that they remit more to households with large herds, which is consistent with a strategy to secure inheritance. However, it is also common for sons to keep their cattle with those of the household, so it may also be that, along the lines suggested by the "exchange" hypothesis, remittances compensate the recipients for maintaining and expanding the sons' own cattle.

In short, the three potential explanations for the positive relation between remittances and the household's income were all shown to be consistent with the evidence from Botswana. This is not sufficient, however, to disqualify an altruisticbased rationale for remittances. From a dynamic perspective indeed, this pattern of remittances may be reconciled with altruism if, for example, past remittances sent with an altruistic intent have contributed to raise today's income. Testing for such possibilities would require longitudinal data that were not available to Lucas and Stark. 
Lucas and Stark also tested for the insurance hypothesis, which implies that remittances should increase during bad economic times in the rural sector and be directed to households who possess assets with volatile returns. The context of Botswana, situated in a semi-arid tropical region, and the time span covered by the data, allowed for such an inquiry since 1978-79 was a drought year whose severity varied across villages. For each village sampled, the severity of drought was indexed and included in the remittance equation both separately and interacted with (the logarithm of) two familial assets, namely agricultural land and cattle owned. When omitting the interaction terms, the coefficient on the drought index alone proved significantly positive, a finding that could be interpreted as suggestive of either altruism or insurance. Yet, with interactions terms included, existence of drought conditions or possession of more drought-sensitive assets did not stimulate greater remittances per se, but the interactions of drought with these drought-sensitive assets did. This is consistent with rural households sending members to the city for the prospect of insurance.

The work of Lucas and Stark (1985) has generated further empirical work on remittances in different contexts. In particular, positive relationships between transfer amounts and recipients' incomes have repeatedly been uncovered in developing countries, notably by Donald Cox and his co-workers (Cox, 1987; Cox and Rank, 1992, Cox, Eser and Jimenez, 1998). The latter study was dedicated to the analysis of private transfers in Peru, which consist for the most part of remittances. As distinct from Lucas and Stark (1985), whose study encompassed a number of possible motivations, Cox, Eser and Jimenez (1998) concentrated on altruism versus exchange and tested the effect of recipient households' pre-transfer incomes on the size and probability of remittances. Recall that a negative sign is consistent both with altruism and exchange, but a positive sign is in principle incompatible with altruism and consistent with exchange. More precisely, the type of exchange envisioned in their study is a loan repayment of educational investments. This implies that liquidity constraints matter, and that the non-market implicit interest rate reflected in remittances depends on the sides' respective bargaining power.

Cox, Eser and Jimenez (1998) tested these two motives for both ascending (from children to parents) and descending (from parents to children) private transfers in Peru in the mid-1980s, and controlled for social security benefits, gender, marital status, household size, home ownership, education, and for whether transfers were 
transitory or permanent. Analyzing the timing of transfers, they established that transfer receipts and earnings move in opposite directions over the life-cycle (i.e., net recipients are either very young or very old), suggesting that liquidity constraints indeed matter. Probit results for transfers from child-to-parent (which consist mostly of remittances) indicate that the probability of transfer is inversely related to parental income, a finding which is consistent with both altruism and exchange. But the effect of income on the amount transferred, conditional on receiving a transfer, is first positive, then negative (i.e., inverse-U shaped), as suggested by the bargainingexchange hypothesis. The same pattern applies to parent-to-child transfers, leading the authors to conclude that the bargaining-cum-altruism framework appears more powerful than the strong form of the altruistic model. Besides, Cox, Eser and Jimenez (1998) also found that private transfers are targeted toward the unemployed and the sick, a finding consistent with both altruism and insurance; however, public pension transfers and private transfers from children to parents are shown to be complements instead of substitutes, a finding which makes sense in a bargaining framework but is incompatible with altruism. By contrast, Jensen (2003) finds evidence that public pensions crowd out private transfers in South Africa, but only partially (by about a quarter to a third).

The "loan repayment" or "investment" theory is also supported by the study of Ilahi and Jafarey (1999) on Pakistan, with an emphasis on loans aimed at financing international migration costs rather than education. Their argument is that international migration costs are quite substantial and above the financial possibilities of the migrants' close family, requiring financing from larger kinship networks (the "extended family"). And indeed, retrospective surveys of return migrants in Pakistan show that $58 \%$ of them borrowed from relatives to finance the initial costs of their migration, with loans from relatives financing half of the migration expenses (4/5 for those migrants who did rely on relatives from the extended family). However, the loan repayment hypothesis cannot be tested directly since the data on remittances between migrants and households other than their immediate family are generally not available from existing surveys. To circumvent this difficulty, Ilahi and Jafarey (1999) propose an indirect method for tracing such remittance flows, the main testable implication of their model being that remittances to the immediate family and retained savings overseas should fall with the loan from extended relatives. Using data from Pakistan, they find support for this hypothesis, implying that the initial loan from relatives calls 
for subsequent repayment. Their econometric tests also reveal the existence of an upper threshold in pre-migration borrowing.

A number of empirical studies have also focused on inheritance as an enforcement device in securing remittances. Hoddinott (1994) provides strong evidence supporting this theory using data from western Kenya. Hoddinott estimated a remittance function after controlling for two sources of selection bias: (i) the fact that migrants are a non-random group, and, (ii) the fact that remittance behavior depends on the parents' information about migrants' earnings abroad (since migrants with uninformed parents would tend to remit less). Both sources of selectivity-bias were controlled for, using an extension of the Heckman procedure. An interesting implication of this approach is that since rich families only may secure remittances through inheritance, migration tends to increase inter-household inequality. ${ }^{20} \mathrm{~A}$ limit to this approach may be the fact that many resources are collectively-owned in the rural communities rather than family-owned, thus limiting the scope for inheritanceseeking through remittances; however, Osili (2004) finds that the same behavior seems to apply at a community level, with migrants investing more in wealthier communities so as to secure their membership rights.

It has already mentioned that evidence of an insurance mechanism was found in contexts as different as Botswana (Lucas and Stark, 1985) or Peru (Cox, Eser and Jimenez, 1998). Similar results were found for West African countries, notably by Lambert (1994) in the case of Cote d'Ivoire and by Gubert (2002) for Western Mali. The first study showed that risk-aversion positively influences migration, and the second study showed that remittances are instrumental in providing insurance to remaining household, but in a way that depends on the nature of the shock (e.g. climatic change, sickness of a household member, etc.). By contrast, Agarwal and Horowitz (2002) found a negative effect of the number of migrants on remittances sent to Guyana; building on their argument on multiple-migrant households, they took this finding as supportive evidence of altruism instead of insurance.

The study by de la Brière et al. (2002) explores whether remittances to a poor rural region of the Dominican Republic are better explained by reference to insurance or inheritance, two motives for remittances that are not exclusive one of the other.

\footnotetext{
${ }^{20}$ This is consistent (but differently motivated) with the prediction of our investment model; see infra, section 3.2., for discussions on migration and inequality.
} 
Their data reveal that remittances should be treated as censored data (remittances in small amounts are frequently observed) and that more than 75 percent of households with migrants have more than one migrant. Four alternative estimation procedures are compared: OLS, a random-effect model (to account for the clustering effect of the presence of a sibling from the same household), a standard tobit, and a censored remittance model. They show that the relative importance of each motive is affected by the migrant's destination (U.S. or Dominican cities), the migrant's gender, and the composition of the receiving household. Interestingly, insurance appears as the main motivation to remit for female migrants who emigrate to the U.S.; the same result holds true for males as well, but only when they are the sole migrant member of the household and when parents are subject to health shocks. Investment in inheritance, on the other hand, seems to be gender neutral and only concerns migrants to the U.S.

As already explained, the enforcement constraint generally limits the degree of insurance (or whatever is looked for) that may be attained through implicit migration contracts; this, in turn, often implies a sub-optimal migration rate. Obviously, altruism tends to mitigate such inefficient outcomes in that it decreases the cost of enforcement, thereby expanding income-pooling opportunities. This was recently confirmed by Foster and Rosenzweig (2001), who first proposed a theoretical model of risk sharing under imperfect commitment, and then estimated linear approximations of transfer functions using three panel data sets from different rural regions of South Asia. Their results show that, when remittances play an insurance role but do not allow for full insurance due to informational barriers (which give rise to commitment problems), the amounts transferred depend both on contemporary income shocks and on the history of previous transfers (which themselves arose in that same context of impossibility for the members to commit to make first-best statecontingent transfers). On the whole, they demonstrated that altruism reduces but does not eliminate the commitment constraint.

Another potential problem related to asymmetric information raised in the theoretical section concerns the possibility of moral hazard on the recipients' side. Using panel survey data on migration, production and income of Soninke households from the Kayes region in Western Mali, Azam and Gubert (2002) tested the effect of familial insurance on the domestic productivity of remaining households, after controlling for other determinants such as the number of remaining individuals, their 
skills, the type of domestic activity, the size of the cultivated plot, ethnic affiliation, etc. They first constructed a measure of total household productivity by estimating a plot level production function with household-specific fixed effects, and then used this measure to test how productivity is affected by the ratio of the number of migrants to the total number of family members (a ratio interpreted as an indicator of the reliability of the migration-based insurance mechanism). Their results show that recipients' productivity is lower for the ethnic group for which migration is an old tradition and a relatively widespread phenomenon (i.e., for which transfers prospects are the highest), a finding that would seem to provide evidence of opportunistic behavior (moral hazard) on the recipients' side. This is by contrast to Cox, Eser and Jimenez (1998), who found no such evidence in the case of Peru (i.e., private transfers have no impact on labor-supply decisions) or to Joulfaian and Wihelm (1994) reached similar conclusion as to the impact of inheritance prospects on labor-supply incentives in the U.S..

A neglected aspect in this review of the evidence concerns the "social determinants" of remittance behavior. Obviously, most studies control for individual characteristics of both migrants and receiving households, but tend to disregard the social context in which remittances take place. Community characteristics are generally absent from remittance regression analysis, except in very specific cases (e.g., when data on rainfalls or other climate variables at the village level are used to account for the volatility of individual incomes). Two examples will serve as a demonstration of the potential benefits from broadening the analysis so as to include some social determinants of remittances. The first example is from the above-cited study by Azam and Gubert (2002) on the Kayes region in Western Mali. According to Azam and Gubert (2002), it is the fact that the migrants internalize the effect of their transfers on the social prestige of their clan that renders the implicit insurance contract enforceable. This conclusion is formulated after careful examination of the sociocultural context in which migration takes place; using the same anthropological material, the authors emphasize that although such social concern is quite common throughout Africa, it is probably hypertrophied in the case of the Soninke (or Dioula) ethnic group.

The second example is borrowed from Massey and Basem (1992), who used data from four Mexican communities to study the determinants of savings, 
remittances and spending patterns among Mexican migrants. The intriguing result was that dummy variables for community membership explained a large share of the variance in the propensity to repatriate and invest foreign earnings. In the words of Durand et al. (1996, p. 250), who commented on this study, "whatever factors governed migrants' decisions, they operated at the community level, but with only four communities, the investigators could not say what these factors were." This challenging question has been partly answered by Durand et al. (1996) for the "spending" side (see section 3.3.3. below); however, it is clear that further research is required on the social determinants of remittances, possibly in connection with the social networks literature.

On the whole, the evidence from micro surveys confirms that patterns of remittances are better explained as familial inter-temporal contracts than as a result of altruism or other purely individualistic considerations. This is not to deny the importance of individualistic motives, however, since altruism, intentions to return, and prospects for inheritance explain why implicit migration contracts emerge mainly if not exclusively within a familial context.

\section{The macroeconomics of remittances}

Before we begin the analysis of the macroeconomic impact of migrants' remittances, a terminological disclaimer may be required. In the microeconomic section, remittances were defined as an interpersonal transfer between the migrant and his or her relatives in the home country. Accordingly, we did not include temporary migration - understood as a strategy aimed at accumulating enough savings abroad to start an investment project upon return at home - among the different motivations to remit reviewed in that section. At a macro level, however, there are only minor differences between remittances stricto sensu and repatriated savings upon return. ${ }^{21}$ The money saved abroad may be either sent regularly to relatives, deposed on a saving account at home, or repatriated upon return, depending on a host of personal circumstances and on existing financial infrastructures in the home country. ${ }^{22}$ But

\footnotetext{
${ }^{21}$ Moreover, the two are generally mixed together in international statistics.

${ }^{22}$ For example, in the case of Mexico, Durand et al. (1996, p. 259) note that "sending monthly remittances to Mexico and returning home with savings are interrelated behaviors and represent different ways of accomplishing the same thing: repatriating earnings from the United States". They also report that migrants are more likely to remit when they are married, and more likely to return with
} 
from a macroeconomic perspective, the relevant questions are: How much income earned abroad is repatriated to the home country? What kind of households (belonging to what segments of the income distribution) are the most affected? And, are the amounts repatriated used for investment or consumption? On all these aspects, there is no difference in essence between remittances and repatriated savings; in the following, therefore, we use the term "remittances" as a generic label for both.

This section is divided between the short- and long-run effects of remittances on migrants' home economies. While the short-run effects (e.g., on activity and price levels, trade and relative prices, etc.) were the main focus of macroeconomic research on remittances until the end of the 1980s, the emergence of new growth theories has since then given rise to a huge body of research on the growths effects of remittances, notably through their impact on economic inequality.

\subsection{Short-run approaches}

Using static demand-oriented models with sticky prices and wages, traditional shortrun macroeconomics have focused on the effect of international transfers on the aggregate expenditure and the national output. Alongside this standard approach, an important trade-theoretic literature on remittances has developed during the 1980s; based on two-sector (traded and non-traded goods) general equilibrium models, this strand of the literature concentrates on the impact of remittances on relative prices and welfare.

\subsubsection{The standard macroeconomic view}

When remittances constitute a significant source of foreign exchange, they may clearly affect the equilibrium level of the gross national product and other macroeconomic variables. The pure Keynesian model is the oldest model that tries to capture the short-run macroeconomic impact of international transfers. Under the assumptions of sticky prices, fixed exchange and interest rates, and in the absence of supply constraints, this model shows that any shock on the demand side has a disproportionate effect on the national output. Obviously, the magnitude of this 
impact depends on the Keynesian multiplier (which, itself, depends on several parameters such as the marginal propensity to import), and on the size of the transfer shock (which itself depends on the amounts received and on the recipients' marginal propensity to consume remittances). As is well known from the works of Modigliani or Friedman, the propensity to consume must be related to the agents' expectations regarding future income streams (including remittances).

Based on this rationale, Glytsos (1999) proposed a very simple macroeconometric estimation of the aggregate effect of remittances for seven Mediterranean countries. $^{23}$ Using data for 1969-93, he shows that the impact of remittances on consumption, investment, imports, and output varies over time and across countries. For Egypt and Jordan, remittances have a strong influence on output, while evidence of a moderate impact is found for the other countries. In a similar vein, using annual data on Egypt for 1967-91, El-Sakka and McNabb (1999) found that imports financed through remittances have a very high income elasticity, implying that remittances may have low multiplying effects. This is by contrast to Adelman and Taylor (1992), who developed a "Social Accounting Multiplier" matrix to account for the direct and indirect changes in income stemming from remittances to Mexico in the late 1980s. They estimated that each dollar of remittances increased output by a multiplier of 3 when successive rounds of indirect effects were taken into account; this seems quite high indeed, and subject to methodological qualifications clearly exposed in their paper.

An alternative framework for analyzing the short-run economy-wide consequences of remittances is the Mundel-Flemming model of an open economy with fixed prices and a single composite good. In this framework, the effect of international transfers on GDP depends on the assumptions made about the degree of capital mobility and the exchange-rate regime. Let us consider the case of perfect capital mobility: in a pure flexible exchange-rate regime, the equilibrium level of GDP is fully determined on the money market and, hence, is unaffected by international transfers. A rise in the aggregate amount of remittances may stimulate the national expenditure, but this effect is fully compensated by a currency appreciation. Indeed, the purpose of the flexible exchange rate regime is to protect countries against real shocks. In a pure fixed exchange-rate regime, on the other hand, 
the equilibrium of the balance of payments is obtained through variations in the money supply. It is only in this case that a rise in the aggregate amount of remittances may induce an increase of the national income. The Mundel-Flemming model, therefore, provides a very simple framework to account for the complex interactions between the balance of payments constraints and short-run macroeconomic shocks. The overall effect of any demand shock (e.g., a shock induced by remittances) depends on the degree of capital mobility and on the exchange-rate regime.

Modern short-run macroeconomics, however, are based on a systematic exploration of the endogenous determination of wages and prices, a process in which expectations play a critical role. If expenditure shocks (e.g., induced by international remittances) are perfectly expected by wage-setters, the effect on the level of activity would then depend on the extent to which wages and prices are flexible. If prices are fully flexible, there should be no effect on output (in such a setting, only unexpected shocks may generate departures from the natural output level). If prices or wages adjustments are sluggish, however, temporary real effects could be obtained.

To the best of our knowledge, there is no study on the short-run effects of remittances applying the most recent econometric techniques to these modern macroeconomic approaches. Although this could in principle be a useful step, the reason why it has not been attempted so far may be due to the limits inherent to the context of developing countries. A first limit is that the tools of non-stationary econometrics require the construction of long time-series for each macroeconomic variable, and this is generally well beyond the statistical coverage of most developing countries. A second limit, in the same spirit, is that this also requires time-series data for the "remittances" account of the balance of payments, a variable which is very difficult to measure given the variety of legal and illegal transmission channels. ${ }^{24} \mathrm{~A}$ third limit is intrinsic to the economic structure of developing countries; since standard macroeconomic models generally abstract from the informal sector, the degree of financial development, and other institutional (e.g., political instability, ethnic divisions) factors, they are likely to offer a very biased description of developing countries. In any event, their application should be restricted to the

\footnotetext{
${ }^{23}$ The results must be taken with extreme caution given the non-stationarity of some time-series.

${ }^{24}$ See the discussion on this point in the introduction.
} 
analysis of countries at intermediate stages of development and for which the statistical apparatus is sufficiently developed (e.g., Turkey, or Mexico).

\subsubsection{Trade, relative prices and welfare}

Assuming perfect price flexibility and full employment, international trade theory has been applied to analyze the impact of international transfers on relative prices and trade flows. The historical controversy on the "German transfer problem" is a wellknown paradox in international trade theory. Its essence is that a positive transfer may deteriorate the terms of trade of the receiving country when transfers are mostly affected to imports; a possibility of impoverishing transfers thus emerges if the termsof-trade effect dominates the positive income effect. This is similar (but differently motivated) to the "Dutch disease" syndrome, as presented for example in Corden and Neary (1982) or Corden (1984). Nevertheless, it has been shown that the conditions required for impoverishing transfers to materialize are extremely restrictive (Bhagwati, Brecher and Hatta, 1983) so that, on the whole, the idea that international transfers benefit to the receiving countries remains largely accepted.

For the most part, the trade-theoretic literature on international transfers is based on models with homogenous agents. However, it is clear that the welfare effects of international remittances critically depend on the identity of the recipients. Consider, therefore, a small open economy with two factors of production (capital and labor) that are perfectly mobile between two sectors for traded (T) and non-traded goods $(\mathrm{N})$. Agents have identical homothetic preferences. Without remittances, Rivera-Batiz (1982) has shown that emigration adversely affects the welfare of the remaining residents when the economy's capital-labor ratio changes. This is due to the fact that emigration deprives the remaining residents from the opportunity to trade with the migrants in the market for non-traded goods. Introducing heterogeneity in the form of two types of agents characterized by different capital endowments into a similar two-sector model, Quibria (1997) showed that emigration does not affect all categories of residents symmetrically. More precisely, there are winners and losers, with the total welfare effect depending on the particular social welfare function adopted. However, Quibria (1997) argues that emigration is always welfareimproving (irrespective of the welfare criteria adopted) if it is accompanied by enough 
remittances. The division between losers and winners depends on the volume of remittances, the type of migration (who emigrates, i.e., with how much capital?), and the distribution of factor endowments. The latter variable helps explaining the conflicting attitude of workers (emigration raises real wages) and capitalists (emigration reduces the return to capital) toward emigration.

The distinction between losers and winners is also central in the analysis of Djajic (1986). If migrants remit a fraction of their income to the source country, obviously, one has to distinguish between two distinct groups, those who receive the transfers (the related remaining residents - RRR) and those who do not (the unrelated remaining residents - URR), the intuition being that RRR should be better off while URR should be worse off. In fact, what Djajic (1986) demonstrates is that even the URR may benefit from their countrymen's emigration if the flow of remittances is sufficiently large. This case is obtained when the size of the transfer gives rise to an excess demand for non-traded goods by the RRR. This pushes the relative price of non-traded goods upwards and stimulates the purchasing power of the URR.

The diagrammatic representation of this model is given in Figure 3.1., in which we consider the case where Unrelated-Remaining-Residents are net suppliers of non-traded goods. Let AA be the production-possibilities frontier before migration occurs. Given the preferences of domestic agents, the pre-migration equilibrium for this economy is, say, at point E, the point of tangency between AA and a social indifference curve $\mathrm{U}$. Assume now that the frontier moves to $\mathrm{BB}$ as migrants are leaving the country. At constant prices, the new production solution would be $\mathrm{D}$ while the optimal consumption bundle would be K, keeping consumption (and, thus, utility) constant for the remaining residents. Clearly, $\mathrm{K}$ is not an equilibrium since it is characterized by an excess demand for traded goods (remaining residents want to sell DF units of non-traded goods against FK units of traded goods). The relative price of non-traded goods therefore decreases, as does the welfare of the remaining residents (for example, $\mathrm{G}$ may be the new equilibrium).

What happens if migrants send back remittances? Suppose that DH units of traded goods are remitted to the RRRs. At constant prices, this allows them to consume traded and non-traded goods in the pre-migration proportion by exchanging DJ units of traded goods against JK units of non-traded goods with the URRs. This can be achieved at the pre-migration price-system and gives the optimal bundle $\mathrm{K}$ : if 
the flow of remittances is exactly $\mathrm{DH}$, therefore, both the structure of relative prices and the utility level of remaining residents are kept constant. A larger transfer would increase the relative price of non-traded goods, thus leading to an improvement of the URRs' utility (since the latter are net suppliers of non-traded goods). In this configuration, the URRs experience a positive price effect while the RRRs experience a positive income effect and a negative price effect; since the former is likely to dominate the latter, migration and subsequent remittances altogether are paretoimproving. Alternatively, a smaller transfer would reduce the price of non-traded goods and decrease the welfare of the URRs. This shows that, on the whole, the net effect of migration on the welfare of remaining residents depends on the size of remittances.

Fig. 3.1.. Remittances and welfare in a static trade model

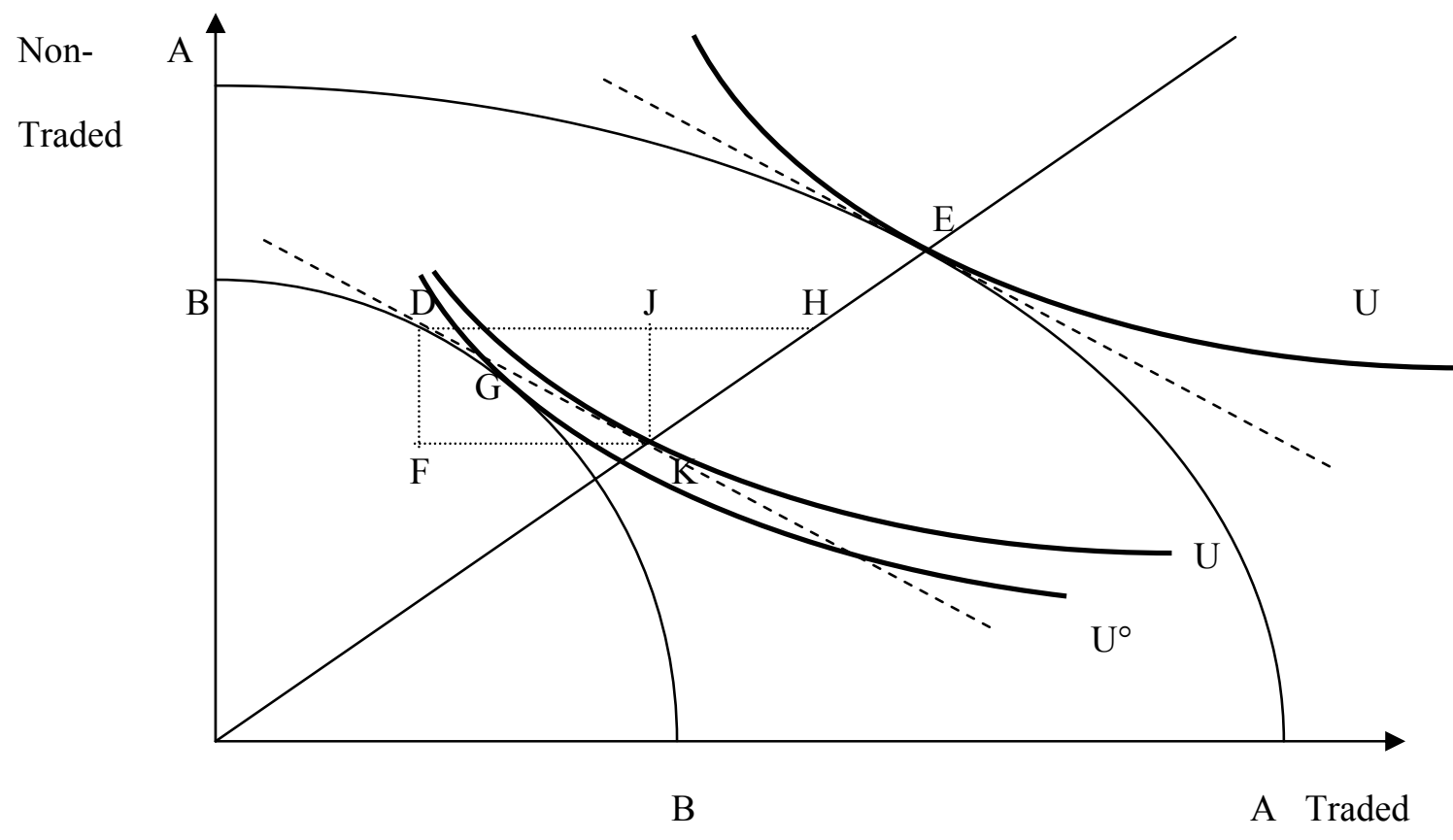

The main criticism that could be addressed to this strand of the literature is that remittances are analyzed for a given level of migration, treated as exogenous. In an attempt to analyze the welfare consequences of remittances and the determinants of international migration (and unemployment) in a unified framework, McCormick and Wahba (2000) recently proposed a model where migration and remittances are jointly determined. They show that for certain values of the parameters, the model exhibits 
multiple equilibria corresponding to different levels of emigration and associated remittances. Interestingly, the high-migration equilibrium Pareto dominates the lowmigration equilibrium, showing that both the URRs and the RRRs may be better off with higher migration rates if lump-sum transfers between residents are available.

\subsection{The long-run view}

It has long been recognized that remittances affect the long-run performance of receiving economies in a way that depends on whether remittances are used for consumption or investment. This issue was central in the controversy on the effects of migration on development during the 1970s; for example, Böhning (1975) or Rempel and Lodbell (1978) explained that, for the most part, remittances were financing consumption and housing expenditures, with limited dynamic effects. At the same time, most socioeconomic studies presented a strongly negative view of remittances; it was argued that remittances were used for conspicuous consumption, thus increasing frustration and resentment among non-migrants; furthermore, remittances were allegedly discouraging labor-supply and effort on the side of the recipients, thus increasing dependency and delaying rural development and change. By contrast, Griffin (1976) or Stark (1978) tried to promote a more optimistic view of remittances, explaining that their negative effects were often unclear or exaggerated and that in fact remittances were often financing productive investments, especially in the rural sector. As Stark (1991, Chapter 14) rightly explained, the additional income from remittances is fungible and investments may well increase even if the actual cash remitted is not invested; moreover, in providing coinsurance to household members, migration in and of itself may allow some households to engage in risky activities (e.g., increased investments in production, adoption of new technologies) with no need for remittances to occur.

About a decade later, during the 1980s, the core of the debate on the growth effects of remittances shifted from productivity to inequality (Stark, Taylor and Yitzhaki, 1986 and 1988, Taylor and Wyatt, 1996). These studies emphasized that remittances actually reduced economic inequality in the origin communities and contributed to alleviate liquidity constraints, thus promoting investments in new agricultural techniques, education, and further migration. However, despite this 
considerable evidence (detailed in the next section) and the strong emphasis put by new growth theories on the interplay between inequality and growth, it is only very recently that the long-run impact of remittances has been reformulated in an endogenous growth framework. In this section, we adopt the view that the growth effects of remittances cannot be dissociated from their distributive effects. We first present two simple models where remittances encourage investment in physical and human capital and may therefore modify the long-run steady-state of the domestic economy. We then present a dynamic extension of the investment model of section 2.1.5. to discuss the impact of remittances on inequality more broadly.

\subsubsection{Liquidity constraint 1 : entrepreneurship. ${ }^{25}$}

Following Mesnard (2001), we extend Banerjee and Newman (1993) for migration, and adopt the simplified model and notations of Ray (1998: Chapter 7). More precisely, we extend Ray's model of occupational choice, inequality and growth to the case where, in addition to existing domestic occupations, individuals may also choose to migrate to a high-wage destination. This migration possibility is subject to a liquidity-constraint, as is the case for accessing to entrepreneurship. In addition to the introduction of a migration possibility, the main departure from Ray (1998) is that we assume the collateral required for accessing to credit markets to be exogenously given (instead of depending on domestic wages). The model is basically a simplification of Mesnard (2001): as distinct from her model, we assume only one type of domestic firms (instead of the individual and corporate types), and the entrepreneurial activity is assumed to involve no risk; with these understandings, we obtain the same qualitative results, but in a much simpler model. We first present the benchmark model based on Ray (1998); the model is then extended to allow for possible migrations and we explore the conditions under which, starting from an initial underdevelopment trap, migration and subsequent remittances allow for a shift towards the efficient long-run equilibrium.

\footnotetext{
${ }^{25}$ This section is based on Rapoport (2002).
} 


\section{i) The closed economy benchmark case}

Consider an economy consisting of a continuum of one-period lived individuals distributed over a continuum of wealth, $\Omega$. The distribution of wealth is denoted by $G(\Omega)$, and the size of the population is normalized to unity. Agents may work in the subsistence sector (in this case they receive a fixed minimal wage, $\underline{w}$ ) or work as salaried workers in the industrial sector (in this case they receive a wage $w$, endogenously determined on the domestic labor market), or become entrepreneur. Becoming an entrepreneur implies incurring a start-up cost $I$ to be repaid with interest $r$ at the end of the period; production requires hiring a given number of workers, $m$, whose total output value is given by $q$. Profits, therefore, depend only on domestic wages, $w$, and on the parameters $I, q, m$, and $r$ :

$$
\pi=q-m w-I(1+r)
$$

A central assumption is that for most individuals, the initial wealth inherited from the previous generation is lower than the start-up cost required for becoming an entrepreneur. Consequently, most individuals (without loss of generality, we assume this is the case for all individuals) must rely on the credit market to finance their entrepreneurial projects. To prevent default in repayment, however, loan contracts stipulate the wealth threshold to be put as collateral before the loan is transferred. This means that individuals with insufficient wealth to be put as collateral cannot access to credit markets and, thus, to entrepreneurship. To determine the critical collateral, one has to compare the amount to be repaid (and gained in case of default), $I(1+r)$, to the cost of defaulting, which includes the value of the lost collateral, $\Omega(1+r)$, and the expected value of a legal or social sanction, $E(S)$. Therefore, credit suppliers know that borrowers would honor the loan repayment if:

$$
\Omega>I-\frac{E(S)}{1+r} \equiv \Omega^{*}
$$

This condition determines the critical wealth threshold below which individuals have no access to entrepreneurship.

The dynamics of this model is extremely simple. Suppose that, at the end of his life, each agent gives birth to one child, bequeaths a fraction $b$ and consumes a fraction $1-b$ of his life-time income, $\Omega(1+r)+y$, where $y$ denotes the income earned over the period. The dynamics of wealth within a given dynasty is then governed by: 


$$
\Omega_{+1}=b[\Omega(1+r)+y]
$$

where $b<(1+r)^{-1}$ may be interpreted as the prevailing degree of intergenerational altruism. This latter assumption ensures that individual wealth converges toward a long-run steady-state:

$$
\Omega^{s s}=\frac{b y}{1-b(1+r)}
$$

The endogenous determination of wages is a central element in this model. When the economy is closed to migration, the labor demand is given by:

$$
L D=\left\{\begin{array}{c}
{\left[1-G\left(\Omega^{*}\right)\right] m \text { if } w<\bar{w}} \\
0 \text { if } w \geq \bar{w}
\end{array}\right.
$$

with $\bar{w} \equiv \frac{q-I}{1+m}$, the wage rate such that individuals are indifferent between being an entrepreneur or a salaried worker. For any higher rate indeed, the number of entrepreneurs and, therefore, the demand for labor, would fall to zero, while for any lower rate, the demand for labor is proportional to the number of entrepreneurs, which depends on the distribution of wealth.

As to the labor supply, it is positive only when the equilibrium wage rate is higher than, or equal to, the subsistence wage, $\underline{w}$, and is determined by the proportion of agents having no access to credit markets when $w$ lies between $\underline{w}$ and $\bar{w}$. Finally, when $w$ is higher than $\bar{w}$, everybody wants to be a salaried worker. This gives:

$$
L S=\left\{\begin{array}{c}
0 \text { if } w<\underline{w} \\
G\left(\Omega^{*}\right) \text { if } \underline{w} \leq \bar{w}<\bar{w} \\
1 \text { if } w \geq \bar{w}
\end{array}\right.
$$

As apparent from Figure 3.2, there are two possible labor-market equilibria. An efficient equilibrium obtains if the degree of prevailing inequality is relatively limited. In this case, the proportion of agents without access to entrepreneurship is sufficiently low so that $G\left(\Omega^{*}\right)<\left[1-G\left(\Omega^{*}\right)\right] m$, implying that the equilibrium wage rate is $\bar{w}$ and the economy is in an efficient state (Figure 3.2a). A second possible equilibrium emerges when the initial distribution of wealth is characterized by a high degree of inequality. In this case, the proportion of constrained agents is high, so that 
$G\left(\Omega^{*}\right)>\left[1-G\left(\Omega^{*}\right)\right] m$. The equilibrium wage rate is then equal to the subsistence wage, $\underline{w}$, and the economy is in an inefficient state (Figure $3.2 b$ ).

Figure 3.2: The labor market equilibrium ${ }^{26}$

Fig. 3.2a: The efficient equilibrium

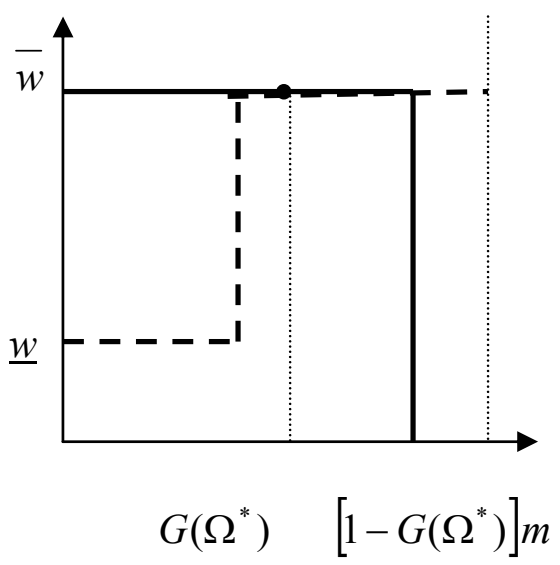

Fig. 3.2b: The inefficient equilibrium

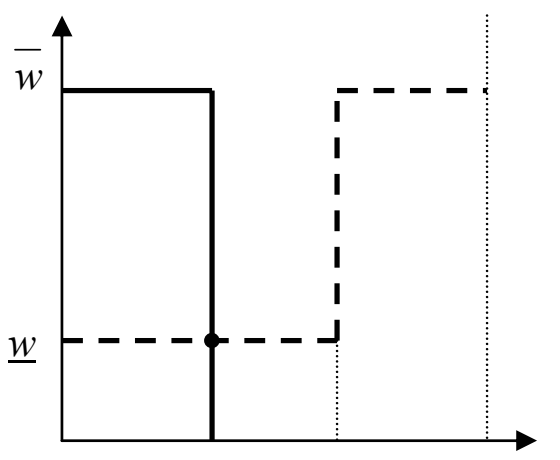

$\left[1-G\left(\Omega^{*}\right)\right] m G\left(\Omega^{*}\right)$

The initial distribution of wealth fully determines the type of equilibrium observed in the short-run. In the long run, the initial distribution of wealth matters only if social mobility is limited: notably, a poor (inefficient) economy will be stuck in a poverty trap if the following condition holds:

$$
b\left[\Omega^{*}(1+r)+\underline{w}\right]<\Omega^{*}<b\left[\Omega^{*}(1+r)+q-\underline{w} l-I(1+r)\right]
$$

\section{ii) The effects of migration and remittances}

Consider now a poor economy for which condition (3.7) holds, but where individuals face a possibility of emigration to a high-wage destination at a fixed $\cos t c$. Assuming that wages at destination are unaffected by immigration, without loss of generality, the foreign wage is set at $\bar{w}$, with $\bar{w}-c>\underline{w}$. Since the migration cost has to be incurred at the beginning of the period, candidates to emigration are subject to a liquidity constraint, $\Omega>c$. If $c$ is higher than $\Omega^{*}$, emigration is not a relevant option since an individual of wealth $\Omega^{*}$ would choose to become an entrepreneur in the home country rather than emigrate. If $c$ is lower than $\Omega^{*}$, however, some workers would opt for

\footnotetext{
${ }^{26}$ For diagrammatic convenience, we assume in Figure 3.2. that $m=1$.
} 
emigration and subsequently transfer a given fraction, $b$, of their foreign income (net of migration cost). A first and immediate (although not interesting) effect of emigration, therefore, consists in a reduction of the labor supply, which becomes $G(c)$; we neglect this first effect, which is likely to be minute, and concentrate on the more realistic (and more interesting) case where emigration has no direct impact on labor-market outcomes but, rather, an indirect impact through migrants' intergenerational transfers. To evaluate their dynamic effects, three cases have to be distinguished, depending on the extent of social mobility generated by remittances:

- If $b\left|\Omega^{*}(1+r)+\bar{w}-c\right|<\Omega^{*}$, there is no mobility since intergenerational transfers have no dynamic effects; the steady-state wealth of a migrant's offspring remains below the critical threshold required for accessing to entrepreneurship;

- If $\left.b \mid \Omega^{*}(1+r)+\bar{w}-c\right]>\Omega^{*}$ and $b[c(1+r)+\underline{w}]>c$, there is full mobility in that migrants' descendents gain access to entrepreneurship and domestic workers' descendents gain access to migration and ultimately, to entrepreneurship. The economy then converges to the efficient solution. However, the same efficient outcome may be obtained with less intergenerational mobility; more precisely:

- If $b\left[\Omega^{*}(1+r)+\bar{w}-c\right]>\Omega^{*}$ and $b[c(1+r)+\underline{w}]<c$, there is partial mobility in that migrants' descendents progressively become entrepreneurs while domestic workers' descendents remain in their origin condition. This is the case apparent on Figure 3.3, which depicts the dynamics of wealth within dynasties in the case of partial mobility:

Fig. 3.3.: The dynamics of wealth within dynasties

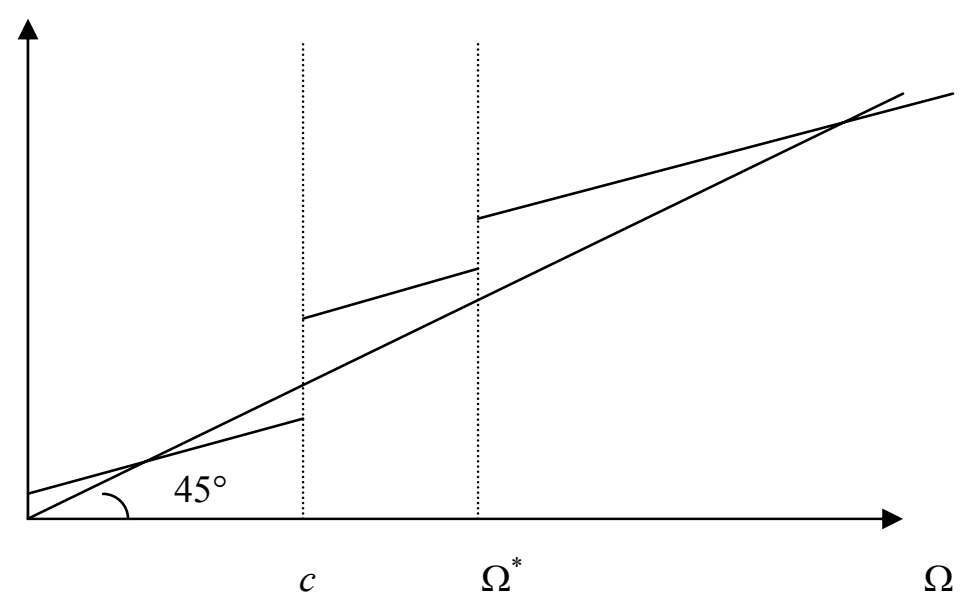


In this configuration, remittances induce a change in the long-run equilibrium of the economy providing that an excess demand of labor appears at the wage rate $\underline{w}$. Formally, this is realized if $G(c)<[1-G(c)] m$. In this case, the economy converges to its long-run efficient equilibrium, and emigration eventually comes to an end.

\subsubsection{Liquidity constraint 2: human capital.}

Assume now that human capital is the engine of growth, and that liquidity constraints impinge on human capital formation. In the same spirit as above, we explore how international remittances may modify the long-run steady-state of a developing economy initially stuck in a poverty trap. We consider an economy where individuals live for two periods. In the first period, they earn a minimal wage $\left(w_{m}\right)$, receive a transfer $(T)$ from the previous generation, and have the possibility to participate in an education program at a given cost normalized to unity. As in Perotti (1993), the decision to invest in education, $e$, is taken subject to a liquidity constraint: savings cannot be negative at the end of the period. This gives:

$$
e=\left\{\begin{array}{l}
1 \text { if } T \geq 1-w_{m} \\
0 \text { if } T<1-w_{m}
\end{array}\right.
$$

The parental transfer fully determines the educational investment. The initial distribution of transfers is denoted by $F(T){ }^{27}$ In the second period, income is endogenous and given by $w_{+1}(1+R e)$, where $w_{+1}$ is the wage rate at time $t+1$ and $R$ is the return to education. As is commonly assumed in this literature, we assume a threshold intra-generational externality such that the wage rate depends on the proportion of educated workers in the home country. Denoting that critical proportion by $\tilde{\mu}$, we write:

$$
w=\left\{\begin{array}{l}
\bar{w} \text { if } \mu \geq \tilde{\mu} \\
\underline{w} \text { if } \mu<\tilde{\mu}
\end{array}\right.
$$

As in the previous model on entrepreneurship, we assume that each old agent transfers a fraction $b$ of his second period income to his child. The evolution of the

\footnotetext{
${ }^{27}$ Time subscripts are eliminated to simplify the notations.
} 
economy, therefore, depends on two main factors: the equilibrium wage rate, and the distribution of transfers. Since the wage rate can only take two values, the dynamics of the model can easily be expressed in terms of $T$. In the closed economy, only two types of equilibrium can emerge, and the dynamics of transfers is given by:

$$
T_{+1}=\left\{\begin{array}{c}
b w_{+1} \text { if } T \leq 1-w_{m} \\
b w_{+1}(1+R) \text { if } T>1-w_{m}
\end{array}\right.
$$

A poverty trap is a situation in which $\mu<\tilde{\mu}$ and $w=\underline{w}$. It is obtained if those who do not have access to education do not transfer enough to allow their children to invest in education $\left(b \underline{w}<1-w_{m}<b \underline{w}(1+R)\right.$ and if the proportion of educated is low $\left(F\left(1-w_{m}\right)>1-\tilde{\mu}\right)$. A high-income solution with $\mu=1$ and $w=\bar{w}$ obtains if, at the high-wage equilibrium, all agents opt for education $\left(b \bar{w}>1-w_{m}\right)$. In the following, we consider the case of a developing economy that is initially stuck in a poverty trap.

Assume now that people may migrate in the second period to a rich country, characterized by a high-income equilibrium (i.e., the foreign wage is $\bar{w}$ ). At the end of the second period, migrants return to their home country and transfer their accumulated savings to the next generation. Migration involves two types of costs: a fixed cost $c$, which has to be financed through first-period savings, and, given the fact that since people generally prefer living in their country of origin, a subjective cost such that one dollar earned abroad is discounted to $k, 0<k<1$. Assume moreover that the migration cost is lower than the cost of education (for if it was not, migration prospects would have no impact): $c<1$. In this configuration, the population in the home country may be split between four distinct groups characterized by different amounts of intergenerational transfers received: group A has no access to education or migration, group $\mathrm{B}$ has access to migration but not to education, group $\mathrm{C}$ has access to education or migration but not to both, and group D has access to both education and migration. This is apparent from the next graph:

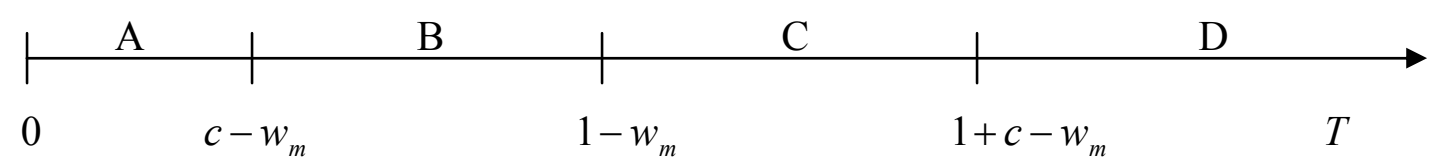


The dynamics of transfers within each group is then governed by:

$$
\begin{aligned}
& \text { Group } A: T_{+1}=b \underline{w} \\
& \text { Group } B: T_{+1}=b \operatorname{Max}\{\underline{w} ; \bar{w} k\} \\
& \text { Group } C: T_{+1}=b \operatorname{Max}\{\underline{w}(1+R) ; \bar{w} k\} \\
& \text { Group } D: T_{+1}=b \operatorname{Max}\{\underline{w}(1+R) ; \bar{w}(1+R) k\}
\end{aligned}
$$

It should be noted that the poorest group (A) is unable to extract itself from poverty unless the proportion of educated becomes high enough to modify the wage rate from $\underline{w}$ to $\bar{w}$. Since groups $\mathrm{C}$ and $\mathrm{D}$ always have access to education, the potential for an increase in the proportion of educated is concentrated within group B. Depending on how intergenerational transfers impact on educational investments within this group, the whole picture may or may not be modified. More precisely, if $1-F\left(c-w_{m}\right)<\tilde{\mu}$, the increase in the number of educated within group B is not significant enough to impact on the determination of the wage rate. However, if $1-F\left(c-w_{m}\right) \geq \widetilde{\mu}$, changes in educational choices within group B have an impact on the determination of the wage rate.

Formally, three cases must be distinguished:

- if $\bar{w} k<\underline{w}$, migration costs are so high that there is no migration at all and, consequently, no departure from the initial equilibrium;

- if $\underline{w}<\bar{w} k<\underline{w}(1+R)$, groups $\mathrm{B}$ and $\mathrm{D}$ opt for migration. ${ }^{28}$ The proportion of educated within the younger generation increases if the children from Group B gradually gain access to education, i.e., if $b \bar{w} k>1-w_{m}$;

- if $\underline{w}<\underline{w}(1+R)<\bar{w} k$, groups $\mathrm{B}, \mathrm{C}$ and $\mathrm{D}$ emigrate and their transfers allow for the next generation to invest in education.

Intuitively, the possibility of an economic take-off depends on the proportion of migrants in the middle-income group and on the amounts remitted. More precisely, the size of group B must be sufficiently large (formally, we must have

\footnotetext{
${ }^{28}$ This change on the supply-side may be sufficient to raise the wage rate up to $\bar{w}$ (formally, this would be the case if $\mathrm{C} /(\mathrm{C}+\mathrm{A})>\widetilde{\mu}$, with $\mathrm{C}$ and $\mathrm{A}$ denoting the respective sizes of the eponymous groups). However, in the same spirit as in the previous section, we neglect that possibility since it would make remittances irrelevant.
} 
$\left.1-F\left(c-w_{m}\right) \geq \tilde{\mu}\right)$, the members of group B must opt for migration (formally, $\underline{w}<\bar{w} k)$ and intergenerational transfers within this group must be such that they allow future generations to access to education (formally, $b \bar{w} k>1-w_{m}$ ). If these three conditions hold simultaneously, then the economy converges to its long-run efficient steady-state.

\subsubsection{Migration, remittances and inequality: a dynamic approach}

The two simple models above analyzed how the initial distribution of wealth conditions the long-run steady-state of the economy in the presence of capital market imperfections. In such a context, we exposed the basic mechanisms whereby migration and subsequent remittances may represent a private solution to overcome liquidity constraints. A central assumption in these models is that familial wealth is an asset accumulated over time and transmitted across generations. In the rural regions, this asset generally takes the form of a plot of land, the quality and quantity of which determines the family's income potential. As explained in the microeconomic section, migration incentives are stronger for poor families, but rich families are less constrained; as a result, the exact composition of migration flows in terms of social origin is a priori unclear. In addition, migration decisions may also be affected by the level of information on job opportunities at destination, which may be related to skills and income, or by incentive compatibility constraints (e.g., wealthy households have a stronger enforcement power to secure remittance through inheritance).

In this discussion, migration costs play a critical role since they determine the wealth threshold at which a given family may or may not access to migration. Until now, these costs have been treated as exogenous; this may be adapted to situations where migration costs mainly include transportation and border crossing expenditures. However, this may not be adapted when information costs (e.g., search process for a destination, and for a job at destination) are significant; in this case, we know thanks to an impressive body of sociological literature that migration costs tend to decrease as the size of the relevant network of migrants at destination increases. ${ }^{29}$ Such

\footnotetext{
${ }^{29}$ Among the contributions to this literature, the work of Douglas Massey and his co-workers on Mexican immigrant networks has been particularly influential. See Massey, Goldring and Durand (1994), Durand et al. (1996), or Massey and Espinoza (1997).
} 
network effects have also been recognized more recently in the economic literature (e.g., Carrington, Detragiache and Vishwanath, 1996, Bauer, Epstein and Gang, 2002, Munshi, 2003, McKenzie and Rapoport, 2004). An immediate implication is that the impact of remittances on economic inequality is likely to vary over time since migration can be viewed as a diffusion process with decreasing information costs. This question has been analyzed in a number of empirical studies detailed below, suggesting that the dynamics of migration and remittances may be characterized by a "trickle down" effect: in the presence of liquidity constraints and initially high migration costs, high-income groups only can access to higher income opportunities abroad and, hence, remittances tend to increase inter-household inequality at origin; as the number of migrants increases, however, migration costs tend to decrease, thus making migration affordable to low-income households; ultimately, economic inequality deceases.

To show this formally, we extend our investment model of section 2.1.5 to the case where migration costs are endogenously determined in the presence of network effects. In doing so, we derive some conditions under which remittances may increase or decrease inequality at origin; interestingly, the model generates the possibility of a Kuznets-type relationship between economic inequality and migration history. For the sake of simplicity, we use a very simple measure of income dispersion, namely, the income ratio between the richest and the poorest household. We denote by $\bar{\alpha}$ and $\underline{\alpha}$ the technological characteristics of rich and poor households, respectively (with $\bar{\alpha}>\underline{\alpha}$ ). Given equation (2.37) with $m=0$, the closed economy income ratio is simply $\sigma_{c l}=\frac{\bar{\alpha}}{\underline{\alpha}}$; we hereafter refer to this ratio as to the "intrinsic technological ratio".

In an economy open to migration, this ratio becomes:

$$
\sigma_{o p}=\frac{\bar{\alpha}-0.5 \bar{\alpha} \beta-\bar{m}^{e f f} c+\bar{\alpha}\left(1-\bar{m}^{e f f}\right)-0.5 \bar{\alpha} \beta\left(1-\bar{m}^{e f f}\right)^{2}+\bar{m}^{e f f} I^{m}}{\underline{\alpha}-0.5 \underline{\alpha} \beta-\underline{m}^{e f f} c+\alpha\left(1-\underline{m}^{e f f}\right)-0.5 \underline{\alpha} \beta\left(1-\underline{m}^{e f f}\right)^{2}+\underline{m}^{e f f} I^{m}}
$$

where $\bar{m}^{\text {eff }}$ and $\underline{m}^{\text {eff }}$ are the actual numbers of migrants sent by rich and poor households, respectively (obviously, this is determined by the minimum between the optimal and constrained numbers - see equations (2.36) and (2.38) above). 
Depending on the size of migration costs, the regime in which rich and poor households operate, and the "intrinsic technological ratio", migration and induced remittances may modify the income range positively or negatively. A simple simulation illustrates this result. We use the same set of parameters as in section 2.1.5, except that: (i) $\underline{\alpha}=3$ and $\bar{\alpha}$ varies from 4.5 to 31.5 (i.e., the intrinsic technological ratio varies from 1.5 to 10.5 ), and, (ii) the migration cost varies from .5 to 12.5 . Figure 3.4 represents the open economy income ratio in deviation from the intrinsic technological ratio, i.e., the endogenous variable $\sigma_{o p} / \sigma_{c l}$. A value above 1 (respectively below 1) indicates an increase (respectively, a decrease) in economic inequality as a result of the migration process. Clearly, for low migration costs, both types of households are unconstrained so that migration and remittances reduce the income range at origin whatever the initial income gap. The opposite result, however, is not necessarily true. For high migration costs, poor households are definitely more constrained so that inequality should increase ceteris paribus. However, it may also be optimal for some rich households to reduce migration from among their ranks, so that the overall effect of migration costs on economic inequality is ambiguous.

The dynamic extension of this discussion is obvious. Consider a constant level of intrinsic technological gap, and suppose that past migration is such that migration costs are relatively high. At an early stage of the diffusion process, remittances are concentrated on high-income classes and inequality increases. In the long run, a decrease in inequality obtains if migration costs decrease sufficiently, as apparent from Figure 3.4. However, Docquier and Rapoport (2003) demonstrated that the same prediction of an inverse U-shaped relationship between migration and inequality may result from the interplay between remittances, the evolution of wages on the local labor market (a notable features of their model is to capture the impact of migration on the domestic supply and demand of labor), and the intergenerational transmission of wealth, with no need for migration costs to decrease over time thanks to network effects. In particular, in their model with exogenous migration costs, they show that while migration and remittances always contribute to reduce wealth inequality, they may first increase income inequality before a trickle-down effect is observed; for this to occur, migration incentives must be sufficiently high for relatively affluent households, a situation which requires initial inequality to be sufficiently low. 
Figure 3.4.: Remittances and inequality - A numerical simulation

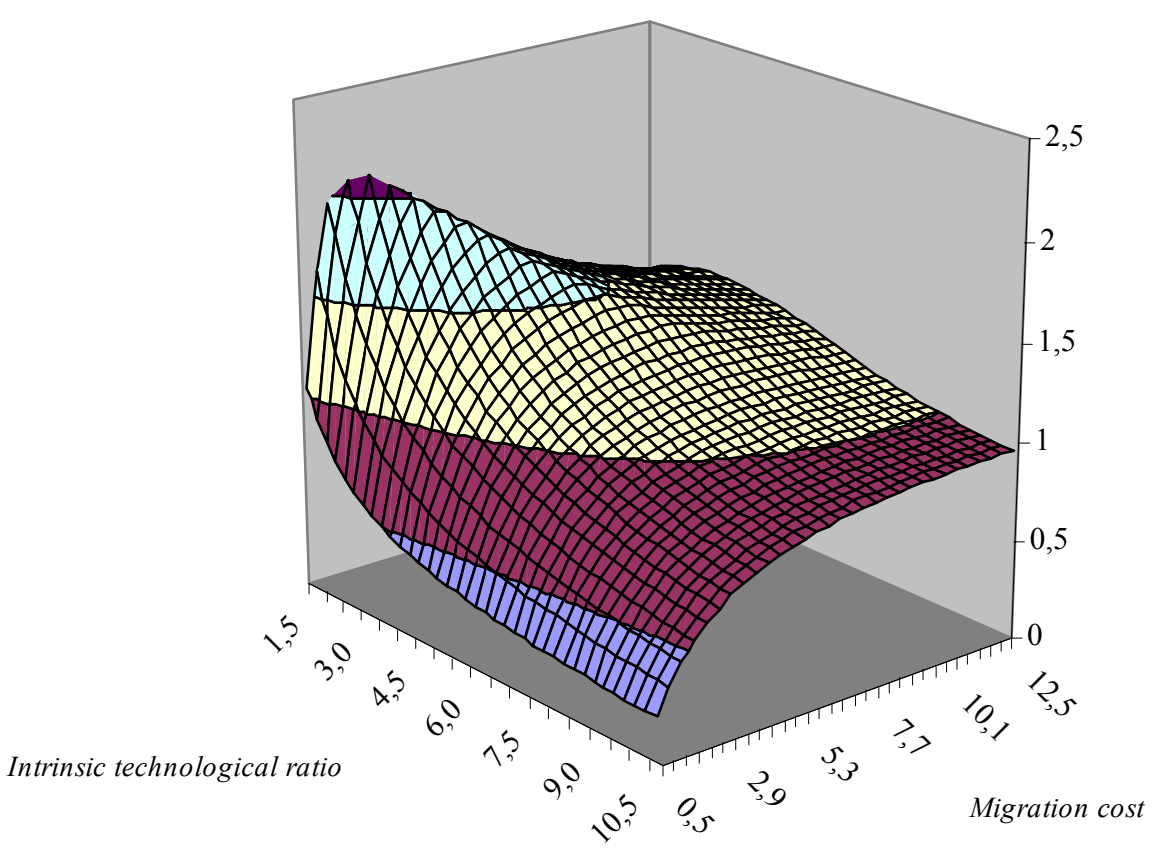

\subsection{Evidence on the growth effects of remittances}

The theoretical presentation above has underlined that the growth potential of remittances depends on their impact on productivity and inequality in the origin communities. Given the poverty of comparative macroeconomic data on remittances (cf. the introduction to this chapter), the evidence presented is all from case studies based on micro data. The only recent cross-country study based on macroeconomic statistics we are aware of is the recent IMF study by Chami, Fullenkamp and Jahjah (2003). Builiding on the idea that remittances take place under asymmetric information and are likely to generate moral hazard problems (see section 2.1.4.), they argue that remittances can have a negative effect on economic growth in receiving countries. They test this prediction using aggregated panel data for 113 countries and, applying various econometric techniques, find a negative effect of remittances on growth after controlling for the investment/GDP ratio, regional dummies and other control variables. However, Chami et al. (2003) disregard the possibility that, due to 
liquidity constraints, remittances could affect investments (thus making the investment/GDP ratio endogenous) and human capital formation, the latter variable being completely absent from their analysis.

\subsubsection{Migration, remittances and inequality}

We know from the theoretical discussion above that migration and remittances have an ambiguous impact on inequality at origin; and indeed, the results from empirical studies are mixed. Early efforts to measure the impact of remittances on inequality treated remittance income as an exogenous transfer, and compared Gini coefficients with and without the inclusion of remittance income. Following this approach, Stark, Taylor and Yitzhaki (1986 and 1988) analyzed household data from two Mexican villages, one with a relatively recent Mexico-to-U.S. migration experience, and one with a longer history of migration. Their findings indicate that the distributional impact of remittances strongly depends on the village's migration history, which in fact captures the magnitude of migration costs. They showed that income dispersion was decreased when migrants' remittances were considered in both villages, but more so in the second village, characterized by a longer migration tradition. From these observations, they derived the general conclusion that "the effect of remittances on inequalities over time depends critically upon how migration-facilitating information and contacts become diffused through the village population. If contacts and information are not household specific, that is, if there is a tendency for them to spread across household units, then migration and receipt of remittances by households at the lower end of the income distribution is likely to occur. This would erode and possibly reverse any initially unfavorable effects of remittances on income inequality" (Stark, Taylor and Yitzhaki, 1986, p. 724). Following similar methods, Milanovic (1987) also tested for the possibility of such a "trickle down" effect using panel data from the 1973, 1978, and 1983 Yugoslavian household surveys. He found no empirical support for this hypothesis; instead, his results showed that remittances tend to raise inequality, although their effects differed over the periods and social categories considered (it was mainly for agricultural households that an inequalityenhancing effect was found). 
Noting that migrant workers would otherwise be working and earning income at home, Adams (1989) predicts what income would have been without remittances. Using a sample of three villages in Egypt, he then finds that the inclusion of remittances from abroad worsens inequality. In contrast, following the same approach with households from 4 districts in Pakistan, Adams (1992) concludes that remittances have an essentially neutral impact on the rural income distribution. Taylor (1992) and Taylor and Wyatt (1996) note that in addition to the direct immediate impact on income, remittances can ease credit constraints for liquidity constrained households. Using a sample of 55 households from one part of Michoacan in Mexico, they find evidence that remittances translate into greater increases in income for rural households with illiquid assets. By allowing poorer households access to credit, remittances also finance the accumulation of productive assets, increasing future income. These indirect effects of remittances act to equalize incomes, and they find that remittances reduce inequality, with a greater effect once the indirect effects are included. Barham and Boucher (1998) follow on from Adams, in treating remittances as a substitute to home production. Using data from 3 neighborhoods in Bluefields, Nicaragua, they estimate a double-selection model to allow for the counterfactual of no migration and no remittances to impact on the participation decisions and earning outcomes of other household members. Treating remittances as exogenous would lead them to conclude that remittances reduce income inequality, whereas treating them as a substitute for home earnings results in remittances increasing inequality.

Finally, McKenzie and Rapoport (2004) examine the overall impact of migration on inequality in a large number of Mexican rural communities. ${ }^{30}$ This impact is composed of the direct and indirect effects of remittances, multiplier effects of remittances through their spending on products and services produced by other community members (Adelman and Taylor, 1992) and other potential spillover and general equilibrium effects; this also includes the network effects of migration on the costs and benefits of migration for other community members. Using two detailed data sets (the Mexican Migration Project (MMP), a survey consisting of data from 57 rural communities typically located in areas of high migration, and the national demographic dynamics survey (ENADID), which consists of a representative sample

\footnotetext{
${ }^{30}$ Results for economy-wide studies suggest that Mexico-U.S. immigration worsens wage-inequality in both countries (Chiquiar and Hanson, 2002).
} 
of 97 rural communities in Mexico), they confirm that Mexican immigrants to the United States come from the middle of the asset wealth distribution, with the migration probability displaying an inverse-U shaped relationship with wealth. The presence of migration networks, both at the family and at the community level, is found to increase the likelihood of migration, which accords with their ability to raise the expected benefits and lower the costs of migration, and to generate a Kuznets-type relationship between migration and inequality. Indeed, at high levels of migration prevalence, such as occur in many of the MMP communities, they find that migration leads to a reduction in inequality, with asset inequality declining more than consumption or income inequality; however, for the communities with a more diverse migration experience, as those surveyed as part of the ENADID project, migration appears to increase inequality at lower levels of migration stock and then to reduce inequality as one approaches the migration levels prevailing in the MMP communities.

\subsubsection{Remittances and human capital formation}

In Section II we analyzed a first possible link between remittances and education through the "repayment of loans" hypothesis, and detailed a number of empirical studies confirming that in many instances, remittances may be seen as repayment of informal loans used to finance educational investments. A natural interpretation is that it is the prospect of migration (rural-urban or international) that makes education a profitable investment for the family; hence, migration fosters human capital formation provided that not too many educated individuals emigrate out of the country. ${ }^{31}$ This first link may be referred to as a "backward" linkage as remittances are targeted toward the generation that preceded the migrant himself. Along the lines suggested in the theoretical model of remittances and liquidity constraints in Section 3.2.2 above, a second possible link between remittances and education must be considered as remittances also finance education for the next generation (thus creating a "forward" link as well). Since dollars are fungible and education has a relatively high incomeelasticity, one would expect remittances to have significant positive effects on the educational attainments of children from households with migrant members.

\footnotetext{
${ }^{31}$ Note however that there is a growing literature on the possibility of a beneficial brain drain. See for example Beine, Docquier and Rapoport (2001).
} 
However, as Hanson and Woodruff (2002) point out, such households are also often characterized by the absence of one parent; since recent research in education indicates that this could be detrimental to the children's schooling achievements, the overall effect on educational attainments is a priori unclear. ${ }^{32}$

Few studies have looked for evidence on this potential forward linkage between remittances and education. In fact, the only works on remittances and investments in human capital we are aware of are the recent studies by Hanson and Woodruff (2002) on Mexico and by Cox Edwards and Ureta (2003) on El Salvador, which represent an important (and encouraging) step toward documenting the potential growth effects of remittances through human capital formation. ${ }^{33}$

Hanson and Woodruff (2002) used the 2000 Mexican Census to evaluate the effect of remittances on "accumulated schooling" (number of school grades completed, and not only number of years) by 10-15 years-olds, a critical age group. Their preliminary results show that children in households with a migrant member complete significantly more years of schooling, with an estimated increase that ranges from 0.7 to 1.6 years of schooling; interestingly, the gain is the highest for the categories of children traditionally at risk of being dropped from school, i.e., girls and older children (13 to 15 year-olds). These results are robust with respect to the identification procedure (i.e., when migration is treated as endogenous) and the introduction of dummy variables for Mexican States. Cox Edwards and Ureta (2003) reach similar conclusions. Their estimates of "survival functions" show that remittances significantly contribute to lower the hazard of leaving school. This effect would seem to be greater in urban areas, but the mere fact of receiving remittances (irrespective of amounts) is shown to have a very strong effect in the rural areas.

\subsubsection{Remittances, return migration and entrepreneurship.}

Most of the empirical literature on migration and access to entrepreneurship concentrates on return migrants. One reason for this may simply be that the return migration channel is quantitatively more important than the remittances channel.

\footnotetext{
${ }^{32}$ They also point out that the effects of growing up separated from one's birth parent(s) on educational attainments have not yet been explored in the case of temporary separations motivated by economic factors.

${ }^{33}$ This is assuming that human capital formation is good for growth. This is a controversial issue in the empirical growth literature (see Pritchett, 2001).
} 
Another reason has to do with data constraints: while the data sets on return migrants are relatively rich (often including information on pre- and post-migration wealth levels and on savings accumulated abroad), household surveys generally provide no information on the wealth distribution prior to self-employment and do not always track properly the exact uses of remittances. While the relative importance of selfemployment is a distinctive feature of the labor force of most developing countries, ${ }^{34}$ evidence has accumulated that the credit market only plays a minor role in financing investments in small businesses. For example, Mesnard (2004) indicates that during the 1980 s, $87 \%$ of the entrepreneurial projects started by Tunisian return migrants were totally financed through accumulated savings while abroad, with only $13 \%$ receiving complementary financing from governmental programs, and none relying on private bank credits. Similarly, Dustmann and Kirchkamp (2002) show that only $1.2 \%$ of Turkish return migrants who were self-employed in 1988 did resort to bank credits as a major source of financing their start-up costs. In such a context, it is clear that for many prospective entrepreneurs, temporary migration is often the only means for accessing to self-employment.

Among the many case studies that confirm this reality, we present in more details recent studies on Tunisia, Turkey and Mexico. More evidence on return migration and occupational choice may be found in Ilahi (1999) for Pakistan, Massey and Parado (1998) for the central-western region of Mexico, and McCormick and Wahba (2001 and 2003) for Egypt. The latter studies offer additional insights in that they show that in the case of literate migrants, both the amount of savings and the migration duration have a significant positive effect on the probability of entrepreneurship upon return, while the first proposition only holds true for illiterate migrants; this suggests that skill-acquisition may be more important for relatively educated migrants than the need to overcome liquidity constraints. In turn, the fact that skilled migrants, which often originate from the urban areas, benefit more from migration, explains why international return migration tends to deepen rural-urban inequality.

The first case study on Tunisia is due to Mesnard (2004) who uses data collected in 1986 by the Tunisian Settled Abroad Office on Tunisian workers who did

\footnotetext{
${ }^{34}$ For example, the United Nations (2000) estimated that self-employment represents about one third of the nonagricultural labor force in North-Africa in 1990. Woodruff and Zenteno (2001) report data from
} 
work abroad at least once between 1974 and 1986 and returned to Tunisia before the survey date. The survey provides detailed information on the occupation chosen upon return as well as on the savings accumulated abroad up to 1986. The evidence shows that self-employed return migrants have accumulated more than twice as much savings as salaried return migrants, that they have stayed longer abroad, and that less than $8 \%$ of them used the skills acquired abroad after they returned. This is consistent with a story of temporary migration in order to overcome liquidity constraints in the home country where workers choose simultaneously their migration duration and saving effort in the foreign country. A formal test of the model is provided by estimating a probability model of self-employment under borrowing constraints, where potential simultaneous bias is taken into account. The main results show that savings accumulated abroad are alleviating liquidity constraints to self-employment in Tunisia. Interestingly, having a high-education level does not increase the probability to be self-employed upon return, while having a large family increases it, suggesting strong labor market imperfections in Tunisia. The model also implies that an increase in wages in the foreign country or lump sum payments offered by some host countries to migrants conditioned upon return encourage would-be self-employed return migrants to return earlier. But they also induce some workers to stay longer by encouraging them to choose self-employment after return instead of wageemployment, as they would have chosen otherwise.

In a similar line, Dustmann and Kirchkamp (2002) found that $50 \%$ of a sample of Turkish emigrants returning from Germany by 1984 started their own business within four years after resettling thanks to the savings accumulated abroad. Dustmann and Kirchkamp simultaneously tested the migration duration and the type of activity chosen upon return (self-employed, salaried or retired), their working assumption being also that these two decisions are made jointly with the decision on the amount to be saved abroad. Their results show that an increase in the host-country wage is likely to decrease the migration duration for those opting for entrepreneurship after return. Conditioned upon returning, they also show that the level of schooling (which determines the wages earned abroad) increases the probability to opt for selfemployment upon return, and reduces the length of the migration duration. Both

Mexico's National Development Bank showing that firms with less than 15 workers provided $45 \%$ of Mexico's jobs in the manufacturing, commercial and service sectors in 1994. 
results are consistent with the idea that migration is part of a life-cycle strategy to accumulate capital so as to gain access to entrepreneurship in the origin country.

By contrast to these two studies, which relied on specific surveys on return migrants, Woodruff and Zenteno's (2001) study on remittances and the creation of micro-enterprises in the urban areas of Mexico combines three national data sets: the 2000 population Census provides the information on migration rates, a data set from the Bank of Mexico provides an accurate and comprehensive picture of remittances receipts (including repatriated savings), and the data on enterprise investment comes from a national survey of micro-enterprises. Startup costs in Mexico are relatively low (around $\$ 1,000$ ) but vary considerably across sectors, and are almost entirely financed through personal savings and loans from family members and friends; only $2.5 \%$ of the firms received bank credit at startup. In this context, it is clear that remittances have a potentially strong impact on access to entrepreneurship. Woodruff and Zenteno's results show that this is indeed the case, with remittances representing an important financing source for investments in micro-enterprises (i.e., thanks to remittances, more firms are created, and of a higher average size): they estimate that remittances are responsible for $20 \%$ of the capital invested in micro-enterprises throughout urban Mexico (the figure jumps to nearly one-third of the invested capital in the 10 high-migration States). ${ }^{35}$ Interestingly, other things equal, the impact is stronger for female-owned firms; in addition, for owners for which the State of residence differs from the State of birth, networks at origin (i.e., in the region of birth) seem to be more important than those at destination. Their findings not only support the view that access to capital (and, hence, economic inequality) are crucial determinants of investments, they also show that migration is indeed instrumental in overcoming such constraints. Another important contribution of their study is to show that some - if not most - of the growth potential associated with remittances by international migrants originating from the rural areas is in fact located in the urban sector. This implies that the impact of remittances on investment tends to be largely underestimated by studies focusing exclusively on rural communities.

Finally, Mesnard and Ravallion (2001) study more closely possible nonlinearities in the wealth-self-employment relationship. Using the same data set as

\footnotetext{
${ }^{35}$ Woodruff (2002) complements these results in showing that remittances seem to foster investment in micro-enterprises not only directly but also indirectly, in attracting supplementary sources of financing, especially trade credit.
} 
Mesnard (2004), they estimate both a non-parametric linear probability model and a parametric nonlinear model of the choice to be self-employed or not amongst return migrants in Tunisia, allowing for nonlinear effects of savings accumulated while abroad. Controls for heterogeneity are included, and tests are made for selection bias and separability between wealth and the controls. Their results show that savings accumulated abroad are of over-ridding importance in explaining business start-ups by Tunisian return migrants and that their effect is concave. Interestingly, they show that there is no sign of increasing returns at low savings level, suggesting generally low start-up costs. These results indicate that the aggregate self-employment rate is an increasing function of aggregate savings accumulated abroad, but a decreasing function of savings inequality.

\subsubsection{Migration, productivity and rural development}

As mentioned previously, most initial studies of the impact of migration and remittances on rural development adopted a strongly pessimistic view. To put it shortly, the main criticism that many scholars initially put forward was that remittances were unproductive and mostly spent on (sometimes conspicuous) consumption. Part of the explanation for this pessimism, as Taylor et al. (1996) point out, is maybe that community characteristics leading to out-migration simultaneously discourages productive investment. This is exemplified by Durand and Massey's (1992) study on 37 Mexican communities, in which although remittances were shown to be spent mostly on consumption in all communities, the share allocated to production investments greatly varied from village to village; this led them to suggest that, "rather than concluding that migration inevitably leads to dependency and a lack of development, it is more appropriate to ask why productive investment occurs in some communities and not in others" (p. 27). ${ }^{36}$

In line with this research program, Durand et al. (1996) studied 30 Mexican communities located in the States with a long tradition of emigration to the U.S., and showed that the presence in the village of an ejido (production cooperative) significantly increased the likelihood of having remittances spent on production. Similarly - and quite obviously -, at an individual level, the likelihood that a given household would spend a dollar of remittances for productive uses greatly increased 
with access to land and housing ownership, suggesting that on average, less unequal communities at origin would tend to channel remittances towards more productive uses. In a similar spirit, and again for rural Mexico, Taylor and Wyatt (1996) show that remittances are distributed almost evenly across income groups, hence inducing a direct equalizing effect in terms of economic inequality. However, remittances have the highest shadow value for households at the middle-to-low-end of the income distribution; for such households indeed, remittances allow for accessing to productive assets (land) and/or complementary inputs; a second equalizing effect is thereby obtained. This suggests that the impact of remittances on rural development depends not only on the initial distribution of wealth in the origin community (in particular, the presence or absence of an ejido appears critical), but also on a host of factors affecting their shadow value (e.g., degree of liquidity of land rights, costs of complementary inputs, availability of local labor, etc.).

Fortunately, the literature on the effects of migration and remittances on rural development is not limited to Mexico. In particular, two studies undertaken in very different contexts have illuminated the positive impact of remittances on rural productivity. The first study is the influential work of Robert Lucas on the outmigration to South Africa's mines from neighboring countries (Botswana, Lesotho and Malawi) and homelands within South Africa, where Lucas makes clear that the short run decline in rural production due to the loss of labor is more than offset by later increases in agricultural productivity as remittances help raise farm investments (Lucas, 1987). The second study, by Rozelle, Taylor and deBrauw (1999) on rural China, follows along similar lines; however, their results show an overall negative impact of migration on rural output; still, the decrease in output is partly offset by access to capital through remittances.

\section{Conclusion}

We have seen that migration and associated remittances tend to have an overall positive effect on origin countries' long-run economic performance. It is beyond the scope of this survey to evaluate whether emigration is a sustainable development strategy or to ask whether governments should try to impact on the migrants' skill

\footnotetext{
${ }^{36}$ The summaries of Taylor et al. (1996) and Durand and Massey (1992) are borrowed from Durand et al. (1996).
} 
composition or immigration status (e.g., temporary or permanent visas). However, two relatively modest policy issues can be briefly discussed further: i) how to increase the amount of remittances for a given number and quality of migrants; and, ii) how to increase the social value of a dollar of remittances.

The first objective is essentially a matter of financial development, with implications well beyond the issue of remittances. As far as remittances are concerned, however, it is clear that promoting saving accounts in foreign currency and cross-national banking would contribute to a substantial reduction in the level of transaction costs. In some extreme cases, transaction costs on remittances have been estimated at $25 \%$ of the amounts remitted for Latin America (15\% in direct fees for wire-transfers or money orders, plus $10 \%$ in currency exchange). Specific financial incentives for emigrants have been designed in some countries (e.g., accounts in foreign currency in India, Sri Lanka, or Pakistan, bonus on the official exchange rate in Egypt and Turkey), but it is unclear whether the gains from increased remittances are offset by the costs of additional distortions to the financial system. An even less convincing strategy, followed by countries such as China, is to rely on mandatory transfers as a condition to issue exit permits; such policies require State control of the whole process of labor migration and have their own obvious drawbacks in terms of economic freedom and welfare.

The second objective is equivalent to channeling remittances into their most productive uses. With this in mind, several countries have implemented special programs, notably for return migrants: free managerial training for prospective entrepreneurs (Korea, Sri Lanka), reduced tariffs on imported equipment goods (Pakistan), etc. On a broader scale, an alternative frequently raised within international forums (e.g., Lowell, 1997) is to create remittances-based funds, as if the core of the problem was a pure matter of intermediation. On this question - and on a final note -, we would like to make ours the following statement by Durand et al. (1996: 261): “As they elevate a family's standard of living, contribute to business formation, and lead to community improvements, [remittances] represent a tangible accomplishment [...]. The way for policy makers to encourage productive investment is not to harangue migrants about their excessive consumption or to attempt to change their micro-level behavior. Rather, the best way is to pursue macroeconomic policies 
that yield a stable and propitious investment climate and to make expenditures on infrastructures [so as to] ... make investments an attractive, profitable proposition."

\section{References}

Adams, R. (1989): Workers remittances and inequality in rural Egypt, Economic Development and Cultural Change, 38, 1: 45-71.

Adams, R. (1992): The impact of migration and remittances on inequality in rural Pakistan, Pakistan Development Review, 31, 4: 1189-203.

Adelman, I. and J.E. Taylor (1992): Is structural adjustment with a human face possible? The case of Mexico, Journal of Development Studies, 26: 387-407.

Agarwal, R. and A.W. Horowitz (2002): Are international remittances altruism or insurance? Evidence from Guyana using multiple-migrant households, World Development, 30, 11: 2033-44.

Altonji, J.G., F. Hayashi and L.J. Kotlikoff (1992): Is the extended family altruistically linked? Direct tests using micro data, American Economic Review, 82 (5): 1177-98.

Altonji, J.G., F. Hayashi and L.J. Kotlikoff (1997): Parental altruism and inter-vivos transfers: theory and evidence, Journal of Political Economy, 105 (6): 1121-66.

Andreoni, J. (1989): Giving with impure altruism: Applications to charity and Ricardian equivalence, Journal of Political Economy, 97, 6: 1447-58.

Azam, J.P. and F. Gubert (2002): Those in Kayes. The impact of remittances on their recipients in Africa, Mimeo., University of Toulouse.

Banerjee, A.V. and A.F. Newman (1993): Occupational choice and the process of development, Quarterly Journal of Economics, 105: 501-26.

Barham, B. and S. Boucher (1998): Migration, remittances and inequality: estimating the net effects of migration on income distribution, Journal of Development Economics, 55: $307-31$.

Bauer, T., G.S. Epstein and I.N. Gang (2002): Herd effects or migration networks? The location choice of Mexican immigrants in the US, IZA Discussion Paper No 551, August.

Beine, M., F. Docquier and H. Rapoport (2001): Brain drain and economic growth: theory and evidence, Journal of Development Economics, 64, 1: 275-89.

Bernheim, B.D., A. Shleifer and L.H. Summers (1985): The strategic bequest motive, Journal of Political Economy, 93 (6), 1045-1076.

Bhagwati, J., R. Brecher and T. Hatta (1983): The generalized theory of transfers and welfare, American Economic Review, 83: 606-18.

Böhning, W.R. (1975): Some thoughts on emigration from the Mediterranean basin, International Labour Review, 111, 3: 251-77.

Carrington, W.J., E. Detragiache and T. Vishwanath (1996): Migration with endogenous moving costs, American Economic Review, 86, 4: 909-30.

Chami, R., C. Fullenkamp and S. Jahjah (2003): Are immigrant remittance flows a source of capital for development, IMF Working No 03/89.

Chen, K.P. and S.H. Chiang (1998): Migration as portfolio selection, mimeo., York University.

Chiquiar, D. and G. Hanson (2002): International migration, self-selection and the distribution of wages: evidence from Mexico and the United States, NBER Working Paper No 9242, September.

Coate, S. and M. Ravallion (1993): Reciprocity without commitment - Characterization and performance of informal insurance arrangements, Journal of Development Economics, 40: $1-24$.

Corden, W.M. (1984): Booming sector and Dutch disease economics: survey and consolidation, Oxford Economic Papers, 36: 359-80. 
Corden, W.M. and P.J. Neary (1982): Booming sector and de-industrialization in a small open economy, Economic Journal, 92: 825-48.

Cox, D. (1987): Motives for private transfers, Journal of Political Economy, 95(3): 508-46.

Cox, D. and E. Jimenez (1992): Social security and private transfers in a developing country: the case of Peru, World Bank Economic Review, 6(1): 155-69.

Cox, D. and M. Rank (1992): Inter-vivos transfers and intergenerational exchange, Review of Economics and Statistics, 74: 305-14.

Cox, D., Z. Eser and E. Jimenez (1998): Motives for private transfers over the life cycle: An analytical framework and evidence for Peru, Journal of Development Economics, 55: 57 80.

Cox Edwards, A. and M. Ureta (2003): Internation migration, remittances ans schooling: evidence from El Salvador, Journal of Development Economics, 72, 2: 429-61.

de la Brière, B., E. Sadoulet, A. de Janvry and S. Lambert (2002): The roles of destination, gender, and household composition in explaining remittances: An analysis for the Dominican Sierra, Journal of Development Economics, 68, 2: 309-28.

Djajic, S. (1986): International migration, remittances and welfare in a dependent economy, Journal of Development Economics, 21: 229-34.

Docquier, F. and H. Rapoport (1998): Are migrant minorities strategically self-selected?, Journal of Population Economics, 11: 579-88.

Docquier, F. and H. Rapoport (2000): Strategic and altruistic remittances, in L.-A. GerardVaret, S.-C. Kolm and J. Mercier Ythier (eds): The Economics of Reciprocity, Giving and Altruism, London and New York: MacMillan and St. Martin's Press, pp. 285-97.

Docquier, F. and H. Rapoport (2003): Remittances and inequality: a dynamic migration model, CREDPR Working Paper, Stanford University, June 2003.

Duflo, E. and C. Udry (2001): Intrahousehold resource allocation in Cote d'Ivoire: social norma, separate accounts, and consumption choices, BREAD Working Paper No 16, Harvard University, February.

Durand, J. and D.S. Massey (1992): Mexican migration to the United States: A critical review, Latin American Research Review, 27: 3-43.

Durand, J., W. Kandel, E.A. Parrado and D.S. Massey (1996): International migration and development in Mexican communities, Demography, 33, 2: 249-64.

Dustmann, C. and O. Kirchkamp (2002): The optimal migration duration and activity choice after remigration, Journal of Development Economics, 67, 2: 351-72.

El-Sakka, M. I. T., and R. McNabb (1999): The macroeconomic determinants of emigrant remittances, World Development, 27, 8: 1493-1502.

Fafchamps, M. (1992): Solidarity networks in pre-industrial societies: rational peasants with a moral economy, Economic Development and Cultural Change, 41(1): 147-74.

Feinerman, E. and E.J. Seiler (2002): Private transfers with incomplete information: A contribution to the "Altruism-echange motivation for transfers" debate, Journal of Population Economics, 15, 4: 715-36.

Foster, A.D. and M.R. Rosenzweig (2001): Imperfect commitment, altruism, and the family: evidence from transfer behavior in low-income rural areas, Review of Economics and Statistics, LXXXIII (3): 389-407.

Funkhouser, E. (1995): Remittances from international migration: a comparison of El Salvador and Nicaragua, Review of Economics and Statistics, 77, 1: 137-46.

Glytsos, N.P. (1999), Modeling the growth generating capacity of migrants remittances: an application to Mediterranean countries, Mimeo.

Griffin, K. (1976): On the emigration of the peasantry, World Development, 4, 5:, 353-61.

Gubert, F. (2002): Do migrants insure those who stay behind? Evidence from the Kayes Area, Oxford Development Studies, 30, 3: 267-87.

Hanson, G.H. and C. Woodruff (2002): Emigration and educational attainment in Mexico, Mimeo., University of California at San Diego.

Hoddinott, J. (1994): A model of migration and remittances applied to Western Kenya, Oxford Economic Papers, 46: 450-75. 
Ilahi, N. (1999): Return migration and occupational change, Review of Development Economics, 3, 2: 170-86.

Ilahi, N. and S. Jafarey (1999): Guestworker migration, remittances and the extended family: evidence from Pakistan, Journal of Development Economics, 58: 485-512.

Jensen, R.T. (2003): Do private transfers 'displace' the benefits of public transfers? Evidence from South Africa, Journal of Public Economics, 88: 89-112.

Joulfaian, D. and M.O. Wihelm (1994): Inheritance and labor supply, Journal of Human Resources, 29, 4: 1205-34.

Kaufmann, D. and D.L. Lindauer (1986): A model of income transfers for the urban poor, Journal of Development Economics, 22: 337-50.

Lambert, S. (1994): La migration comme instrument de diversification intrafamiliale des risques. Application au cas de la Cote d'Ivoire, Revue d'Economie du Développement, 0 , 2: 3-38.

Lauby, J. and O. Stark (1988): Individual migration as a family strategy: young women in the Philippines, Population Studies, 42: 473-86.

Lowell, L.B. (1997): The role of migrants' remittances in U.S. Latino communities and Latin America and the Caribbean, Mimeo., Inter-American Development Dialogue and Tomas Rivera Policy Institute, December.

Lucas, R.E.B. (1987): Emigration to South Africa's mines, American Economic Review, 77, 3: 313-30.

Lucas, R.E.B. (1997): Internal migration in developing countries, in M.R. Rosenzweig and O. Stark, eds.: Handbook of Family and Population Economics, Amsterdam, North Holland. Chapter 13, Vol. 1.B, pp. 721-98.

Lucas, R.E.B. and O. Stark (1985): Motivations to remit: Evidence from Botswana, Journal of Political Economy, 93, 5: 901-18.

Massey, D.S. and L. Basem (1992): Determinants of savings, remittances, and spending patterns among Mexican migrants to the US, Sociological Inquiry, 62: 186-207.

Massey, D.S, L. Goldring and J. Durand (1994): Continuities in Transnational Migration: An Analysis of Nineteen Mexican Communities, American Journal of Sociology, 99, 6: 1492-1533.

Massey, D.S. and K.E. Espinoza (1997): What's driving Mexico-U.S. migration? A theoretical, empirical and policy analysis, American Journal of Sociology, 102, 4: 93999.

Massey, D.S. and E.A. Parrado (1998): International migration and business formation in Mexico, Social Science Quarterly, 79, 1: 1-20.

McCormick, B. and J. Wahba (2000): Overseas unemployment and remittances to a dual economy, Economic Journal, 110: 509-34.

McCormick, B. and J. Wahba (2001): Overseas work experience, savings and entrepreneurship amongst return migrants to LDCs, Scottish Journal of Political Economy, 48, 2: 164-78.

McCormick, B. and J. Wahba (2003): Return international migration and geographical inequality: the case of Egypt, Journal of African Economies, 12, 4: 500-32.

McKenzie, D. and H. Rapoport (2004): Network effects and the dynamics of migration and inequality: theory and evidence from Mexico, BREAD Working Paper No 63, Harvard University, April.

Mesnard, A. (2001): 'Temporary migration and intergenerational mobility, Louvain Economic Review, 67, 1: 59-88.

Mesnard, A. (2004): Temporary migration and capital market imperfections, Oxford Economic Papers, 56: 242-62.

Mesnard, A. and M. Ravallion (2001): Wealth distribution and self-employment in a developing country, CEPR Discussion Paper DP3026.

Milanovic, B. (1987): Remittances and income distribution, Journal of Economic Studies, 14, 5: 24-37.

Munshi, K. (2003): Networks in the modern economy: Mexican migrants in the US labor market, Quarterly Journal of Economics, 118, 2: 549-99. 
Nitzan, S. (1994): Modeling rent-seeking contests, European Journal of Political Economy, 10, $1: 41-60$.

Osili, U.O. (2004): Migrants and housing investment: theory and evidence from Nigeria, Economic Development and Cultural Change, 52, 4: 821-50.

Perotti, R. (1993): Political equilibrium, income distribution and growth, Review of Economic Studies, 60: 755-76.

Poirine, B. (1997): A theory of remittances as an implicit family loan arrangement, World Development, 25, 5: 589-611.

Pritchett, L. (2001): Where has all the education gone?, World Bank Economic Review, 15, 3 : 367-91.

Quibria, M.G. (1997): International migration, remittances, and income distribution in the source country: a synthesis, Bulletin of Economic Research, 49, 1: 29-46.

Rapoport, H. (2002): Migration, credit constraints and self-employment: A simple model of occupational choice, inequality and growth, Economics Bulletin, 15, 7: 1-5.

Ray, D. (1998): Development economics, Princeton: Princeton University Press.

Rempel, H. and R. Lobdell (1978): The role of urban-rural remittances in rural development, Journal of Development Studies, 14: 324-41.

Rivera-Batiz, F. (1982): International migration, non-traded goods and economic welfare in the source country, Journal of Development Economics, 11: 81-90.

Rodriguez, E.R. (1996): International migrants' remittances in the Philippines, Canadian Journal of Economics, 29,2: 427-32.

Rosenzweig, M.R. (1988a): Risk, implicit contracts and the family in rural areas of lowincome countries, Economic Journal, 393: 1148-70.

Rosenzweig, M.R. (1988b): Risk, private information, and the family, American Economic Review - Papers and Proceedings, 78, 2: 245-50.

Rosenzweig, M.R. and O. Stark (1989): Consumption smoothing, migration and marriage: evidence from rural India, Journal of Political Economy, 97: 905-26.

Rozelle, S., J.E. Taylor and A. deBrauw (1999): Migration, remittances and agricultural productivity in China, American Economic Review (AEA Papers and Proceedings), 89, 2: $287-91$.

Russell, S.S. (1986): Remittances from international migration: a review in perspective, World Development, 14: 677-96.

Stark, O. (1978): Economic-demographic interaction in agricultural development: the case of rural-to-urban migration, Rome: UN Food and Agriculture Organization.

Stark, O. (1991): The migration of labor, Oxford and Cambridge, MA: Basil Blackwell.

Stark, O. (1995): Altruism and Beyond, Oxford and Cambridge: Basil Blackwell.

Stark, O. and D.E. Bloom (1985): The new economics of labor migration, American Economic Review - Papers and Proceedings, 72, 5: 173-8.

Stark, O. and D. Levhari (1982): On migration and risk in LDCs, Economic Development and Cultural Change, 31: 191-6.

Stark, O., J.E. Taylor and S. Yitzhaki (1986): Remittances and inequality, Economic Journal, 28: 309-22.

Stark, O., J.E. Taylor and S. Yitzhaki (1988): Migration, remittances and inequality: a sensitivity analysis using the extended Gini index, Journal of Development Economics, 28: 309-22.

Subramanian, R. (1994): A theory of remittances, CRIEF Working paper, $N^{\circ}$ 9406, University of St-Andrews.

Taylor, J.E. (1992): Remittances and inequality reconsidered: direct, indirect and intertemporal effects, Journal of Policy Modeling, 14, 2: 187-208.

Taylor, J.E., D.S. Massey, J. Arango, G. Hugo, A. Kouaouci, and A. Pellegrino (1996): International Migration and Community Development, Population Index, 62, 3: 397-418.

Taylor, J.E. and T.J. Wyatt (1996): The Shadow Value of Migrant Remittances, Income and Inequality in a Household-Farm Economy, Journal of Development Studies, 32, 6: 899912. 
Thomas, D. (1990): Intra-household allocation: An inferential approach, Journal of Human Resources, 25, 4: 635-64.

United Nations (2000): The World's Women 2000: Trends and Statistics, New York: Department of Economic and Social Affairs.

Woodruff, C. (2002): Firm Finance from the Bottom Up: Micro-enterprises in Mexico, Mimeo., University of California at San Diego.

Woodruff, C. and R. Zenteno (2001): Remittances and micro-enterprises in Mexico, Mimeo., University of California at San Diego.

World Bank (2001): World Tables, Washington: The World Bank.

Zlotnik, H. (1998): International migration 1965-96: An overview, Population and Development Review, 24, 3: 429-68. 